\title{
Apropriabilidade tecnológica e preferências da demanda: o caso da indústria farmacêutica *
}

\author{
Thiago Caliari ** \\ Ricardo Machado Ruiz, *** \\ Marco Valente ${ }^{* * * *}$
}

\begin{abstract}
Resumo
O artigo desenvolve um modelo evolucionário History-friendly para a indústria farmacêutica, com replicações de características específicas ao mercado brasileiro. O ponto de enfoque dessa estratégia de análise foi demonstrar a relevância que diferentes especificações da demanda têm sobre os resultados econômicos e tecnológicos em indústrias com elevado grau de desenvolvimento tecnológico, nos moldes das questões levantadas por Nelson (2013). Em suma, os resultados destacam a importância da consideração da demanda nos modelos evolucionários e são conclusivos nesse objetivo. Mudanças consideráveis nos resultados de mercado, financeiros e tecnológicos de firmas industriais foram alcançadas com modificações na parametrização dos consumidores.
\end{abstract}

Palavras-chave: Indústria farmacêutica; Modelo evolucionário; Heterogeneidade da demanda; Inovação; Medicamentos genéricos.

\section{Abstract \\ Technological appropriability and demand preferences: the case of the pharmaceutical industry}

This paper develops a history-friendly model for the pharmaceutical industry, with replications of features specific to the Brazilian market. The goal was to demonstrate the relevance of demand on the economic and technological progress in industries with high technological development, as pointed out by Nelson (2013). In short, the findings highlight the importance of considering the demand heterogeneity in evolutionary models and are conclusive regarding this objective. Significant changes in the market, financial and technological results for industrial firms were achieved with changes to the parameterization of consumers.

Keywords: Pharmaceutical industry; Evolutionary model; Heterogeneity of demand; Innovation; Generic drugs.

JEL C63, L22.

\section{Introdução}

A teoria evolucionária destaca que o desempenho e a estrutura dos mercados são resultados endógenos do processo competitivo gerado através da busca da

\footnotetext{
*Artigo recebido em 25 de janeiro de 2016 e aprovado em 30 de junho de 2017.

* Professor Adjunto do Instituto Tecnológico da Aeronáutica (ITA), São José dos Campos, SP, Brasil. E-mail: caliari@ita.br.

* Professor Associado do Centro de Desenvolvimento e Planejamento Regional da Universidade Federal de Minas Gerais (Cedeplar/UFMG), Belo Horizonte, MG, Brasil. E-mail: rmruiz@ cedeplar.ufmg.br.

* Professor Associado da University of L'Aquila, Aquila, Itália. E-mail: marco.valente@ univaq.it.
} 
inovação e das condições de imitação. São, segundo destacado em Levin et al. (1985), processos derivados (i) da natureza e força das oportunidades tecnológicas, (ii) da possibilidade e habilidade das firmas na apropriação tecnológica e (iii) da estrutura da demanda.

Apesar da observação dos três determinantes acima expostos, é claro o viés dos modelos evolucionários sobre os itens (i) e (ii). Os modelos de evolução industrial derivados das observações de Schumpeter, chamados comumente de Mark I e Mark II, são observações do autor em relação às propriedades das características estruturais da oferta no que tange às suas capacitações tecnológicas. Em suma, nesses modelos a evolução industrial é dependente das condições de apropriabilidade e cumulatividade tecnológicas ${ }^{1}$.

Os modelos base do desenvolvimento da teoria neoschumpeteriana seguem em sua maioria os mesmos moldes, com uma análise centrada na inovação pelo "lado da oferta", delegando à estrutura da demanda a simplificação da homogeneidade (Nelson; Winter, 1982; Silverberg, Dosi; Orsenigo, 1988, entre outros). Em grande parte dos modelos, essa simplificação é justificada de forma convencional, em geral afirmando uma analogia com mercados com produtos já estabelecidos. Contudo, outras tantas vezes, torna-se interessante a utilização de uma demanda que trate da heterogeneidade dos consumidores tal qual a heterogeneidade dos ofertantes em concorrência tecnológica.

Esse deve ser o caso de um modelo que procure estudar a indústria farmacêutica. A indústria farmacêutica pode ser identificada como um setor onde há baixa cumulatividade tecnológica cruzada entre classes terapêuticas, derivada do processo aleatório de busca de novos medicamentos (Malerba; Orsenigo, 2002; Garavaglia et al., 2012). Posteriormente, no texto, é discutida a questão da baixa cumulatividade tecnológica cruzada entre mercados, o que não significa que haja baixa cumulatividade tecnológica na indústria como um todo, e alta fragmentação da demanda em classes terapêuticas, sendo esses os motivos usuais para explicar a baixa concentração industrial mesmo em um setor com alta intensidade inovativa (Scherer, 1993; Malerba; Orsenigo, 2002; Garavaglia et al., 2012).

A consideração dessa estrutura aliada à estratégia de redução da apropriabilidade tecnológica via política dos genéricos, implementada em vários países a partir da década de 1980, tende a ter um efeito de reconfiguração do mercado com o aumento das possibilidades de imitação de firmas retardatárias, permitindo às mesmas atingirem novas oportunidades competitivas. Com efeito, no caso da indústria farmacêutica brasileira há um reposicionamento setorial, com o aumento da participação de mercado de empresas nacionais produtoras de genéricos após a legislação de 1999.

(1) Sugerimos para os interessados a síntese feita em Andersen (2012) sobre as características dos processos evolucionários na obra de Schumpeter. 
Esse reposicionamento, contudo, não pode ser explicado apenas pelas novas regras estipuladas, pois a existência de produtos de referência com vários anos do mercado, com marca e qualidade reconhecidas, pode estabelecer ainda uma barreira à entrada para concorrentes potenciais. Assim, a diminuição da apropriabilidade tecnológica deve vir acompanhada de uma estratégia de provisão de informação aos consumidores, com vistas a aumentar a homogeneidade dos produtos na percepção da demanda e reduzir o poder de oligopólio das empresas fabricantes de medicamentos de referência. No Brasil, essa estratégia foi perseguida através de campanhas publicitárias para atestar a intercambialidade dos medicamentos, pela padronização da apresentação dos produtos (marca Genérico representada e apresentação do princípio ativo em todos os produtos) e pela compra em larga escala do sistema público de saúde.

Esse trabalho tem o objetivo de mostrar a relevância dos padrões de decisão da demanda no rearranjo estrutural setorial da indústria farmacêutica, por considerar que esse é um caso interessante para exemplificar a relevância da consideração da heterogeneidade da demanda na evolução competitiva setorial.

\section{Heterogeneidade da demanda}

A teoria de concorrência externada nos trabalhos de Schumpeter e da corrente neoschumpeteriana constantemente é resumida em termos das oportunidades de apropriabilidade tecnológica e a cumulatividade dos avanços tecnológicos. Em suma, boa parte da literatura clássica neoschumpeteriana (dentre os principais, Nelson; Winter, 1982; Winter 1984; Pavitt, 1984; Levin et al., 1984; 1985) foca o entendimento da estrutura de mercado nas condições estruturais da oferta e na conduta das empresas respondentes a essas condições.

Dosi (1988), contudo, destaca a importância do tamanho do mercado, de sua taxa de crescimento e da elasticidade da demanda dos produtos na propensão das empresas a inovar nos setores industriais e, concomitantemente, apresentarem modificações na estrutura de mercado ${ }^{2}$. Em alguma monta, a observação de Dosi (1988) é feita no sentido de destacar o apontado por Schmookler (1966) em sua teoria demand-pull. Klepper (1996) e Sutton (1998) discorrem sobre a importância da fragmentação da demanda e diferenciação do produto na conformação estrutural do mercado, qual seja, na prevenção de concentração e grandes modificações estruturais em horizontes de tempo pequenos.

Nelson (2013) destaca que é necessário pensar a demanda e a escolha no contexto de "contínuos fluxos de novas oportunidades e desafios com os quais os consumidores precisam lidar a todo o tempo" (Nelson, 2013, p. 35). Cada inovação oferece ao demandante a possibilidade de mudar sua escolha ou cesta de bens. Também é certo que tais mudanças e escolhas influenciam o modo como setores

(2) "My general point, however, is that the observed sec-toral patterns of technical change are the result of the interplay between various sorts of market-inducements, on the one hand, and opportunity and appropriability combinations, on the other." (Dosi, 1988, p. 1141). 
buscam e selecionam novas inovações. Nelson e Consoli (2010) destacam a instabilidade de preferências devido à variedade de fatores a serem considerados, em particular influenciados pela experiência de consumo dos indivíduos.

Tal instabilidade nas preferências decorre da limitação cognitiva dos consumidores e de processos de seleção de produtos adequados (satisficing), como nos argumentos pioneiros de Simon (1955; 1976; 1978; 1979). Stigler (1961) aponta a relevância da informação na estabilidade dos preços.

Olshavsky e Granbois (1979) também destacam a relevância de vários aspectos intrínsecos ao histórico pessoal como determinantes do processo de decisão de compra, como padrões culturais de consumo e de normas especificadas por grupos de indivíduos - ou pela restrição dos mesmos, além de recomendações pessoais em relações de confiança (imitação de demanda). Em alguns casos envolve percepções na avaliação de poucas alternativas ou ainda com pequena pesquisa externa e critérios simples de comparação ${ }^{3}$.

A decisão da demanda tende ainda a ter maiores complicações em mercados com intensa inovação. Os critérios de comparação frente às alternativas expostas, o conhecimento das especificidades dos produtos no mercado e a consequente ordenação de qualidade dos mesmos tende a ser prejudicada. Essa problemática, aliada aos custos de informação e da necessidade de se incrementar o conhecimento sobre essas variáveis, atesta ainda mais os problemas para a hierarquização de produtos e serviços.

Essa dificuldade na ordenação de preferências é argumentada em Valente (2012). Os consumidores possuem geralmente informações restritas sobre os detalhes tecnológicos de todos os produtos ofertados, os custos de coleta e processamento de informação são elevados e/ou tem pouca motivação para investir tempo e atenção para decisões que são de frequência relativamente baixa e de baixa importância na vida em geral. Em outros casos, o consumidor busca prioritariamente produtos com características específicas e colocam em segundo plano outras dimensões tecnológicas e econômicas ou mesmo minimizam diferenciais de preços, por exemplo. Uma série de estudos destacam esse processo de escolha com limitação racional do demandante frente a mercados com inovação (Windrum ;Birchenhall, 1998; Aversi et al., 1999; Malerba et al., 2007; Windrum et al., 2009; Valente, 2012).

Um estudo de caso interessante para a verificação desses apontamentos é o mercado farmacêutico. A indústria farmacêutica é altamente dependente do nível de investimentos em P\&D, mas também do marketing/promoção de vendas e assistência técnica para a manutenção do posicionamento de mercado de empresas incumbentes. Na mudança de regras regulatórias, como por exemplo a introdução de

(3) Uma série de trabalhos, principalmente no estudo da psicologia cognitiva, tem destacado a influência desses tipos de interações e relações para o padrão de escolha racional dos agentes. Dentre várias leituras, sugerimos Tversky e Kahneman (1986), Thaler (1992) e Slovic (1990). 
medicamentos genéricos, a tendência é que uma nova conformação estrutural seja resultante dessa mudança.

Esse reposicionamento, contudo, não pode ser explicado apenas pelas novas regras estipuladas, pois a existência de produtos de referência com vários anos no mercado, com marca e qualidade reconhecidas, estabelece ainda uma barreira à entrada para concorrentes potenciais. Assim, a diminuição da apropriabilidade tecnológica deve vir acompanhada de uma estratégia de provisão de informação aos consumidores, com vistas a aumentar a homogeneidade dos produtos na percepção da demanda e reduzir o poder de oligopólio das empresas fabricantes de medicamentos de referência. As modificações de mercado passam pelas mudanças nas preferências do consumidor em relação às suas elasticidade-renda e elasticidade preço-cruzada. Essas duas ações conjuntas tendem a fortalecer uma política industrial que vise aumentar a concorrência setorial.

\section{Modelo evolucionário para a indústria farmacêutica}

Podemos extrair algumas características principais da indústria farmacêutica que se procurará explicar pelo modelo History-friendly ${ }^{4}$ a ser desenvolvido nesse capítulo:

1) A estratégia de produção de medicamentos genéricos tem sinalizado ser uma estratégia importante na geração de receita e incremento de mercado (Caliari; Ruiz, 2013);

2) A relevância da estratégia de inovação incremental realizada pelas empresas (Gilbert, Henske; Ashish, 2003; Love, 2003; Ganuza et al., 2009);

3) As estratégias de marketing têm sido utilizadas com frequência pela indústria farmacêutica, principalmente pelas grandes empresas inovadoras, na tentativa de diferenciar seus produtos de referência devido à concorrência de mercado com a expiração de patentes e a consequente entrada de empresas fabricantes de medicamentos genéricos (Angell, 2004; Gagnon; Lexchin, 2008).

A argumentação sobre tais particularidades expostas remete às características e às mudanças no modo de escolha dos agentes demandantes, haja vista a oferta de medicamentos com características técnicas próximas, mas diferenciação de marca totalmente distinta, quais sejam, os medicamentos de referência e os medicamentos genéricos. Pretende-se, assim, responder a seguinte pergunta: como o estabelecimento de distintas preferências e diferentes atributos na decisão de compra por parte do consumidor modifica os resultados inovativos e de mercado de empresas especializadas em medicamentos de referência, medicamentos imitadores e medicamentos genéricos?

(4) Os 'history-friendly models' podem ser destacados como modelos de segunda geração da teoria evolucionária, que buscam coordenar observações teóricas à metodologia modelística explicando fenômenos empíricos, na maioria das vezes ao nível setorial de análise. Para maior detalhamento sobre modelos history-friendly sugerimos a leitura de Malerba et al. (2016). 
Em suma, pretende-se apresentar um modelo history-friendly para uma indústria específica com relevância crucial do "lado da demanda". Essa é uma forma de suscitar maiores desenvolvimentos desse aspecto tão importante no exame de indústrias com alta frequência de inovações.

\subsection{Características fundamentais}

Uma característica específica da indústria farmacêutica é a sua subdivisão em distintos mercados: as classes terapêuticas com baixa cumulatividade tecnológica cruzada entre esses mercados (Malerba; Orsenigo, 2002; Garavaglia et al., 2012).

O modelo replica essa estrutura com firmas atuando em diferentes classes terapêuticas, realizando processos de busca por inovação na totalidade dessas ou apenas em algumas, sendo nesse caso especializadas no desenvolvimento de determinados tipos de produtos. Em linhas gerais, a estrutura de definição do modelo seguirá as especificações apresentadas nos tópicos abaixo:

1) A oferta é fixa e definida por firmas inovadoras, firmas imitadoras e firmas competitivas (Caliari; Ruiz, 2013): as firmas inovadoras e imitadoras realizarão P\&D e poderão inserir produtos inovadores no mercado e as empresas competitivas serão especializadas na produção de medicamentos genéricos. Existem três (3) firmas de cada tipo, sendo a numeração destas estabelecida da menos inovadora para a mais inovadora.

2) Todas as firmas atuam em oito (08) classes terapêuticas distintas ${ }^{5}$. No início da simulação, cada firma oferta um produto em cada classe terapêutica ${ }^{6}$. Porém, se inovarem, é possível durante as simulações a oferta de mais de um produto em cada classe terapêutica (firma multiproduto) ${ }^{7}$.

3) O modelo envolve a possibilidade de patenteamento de produto inovador, caso sejam satisfeitas as condições necessárias para a posse de tal propriedade intelectual.

4) Após o término do período de patenteamento, é facultada às empresas competitivas a produção de medicamentos que são cópias dos medicamentos de marca que tiveram a patente prescrita, justamente os medicamentos genéricos.

(5) A Agência Nacional de Vigilância Sanitária (Anvisa) define a existência de 358 classes terapêuticas distintas. Entende-se, porém, que a definição de um número menor de classes terapêuticas é suficiente para os anseios do modelo, pois já exprime os resultados empíricos necessários para a validação do exercício sem sobrecarregar desnecessariamente o programa de simulação.

(6) Essa estratégia é adotada para permitir homogeneidade competitiva entre as empresas no começo do período de análise. Isso ajuda a garantir que a diferenciação de resultados entre empresas durante a simulação seja proveniente de suas estratégias.

(7) A definição de uma firma multiproduto é bem próxima à definição da grande firma discutida em Chandler (1999), com a possibilidade de crescimento via escala e escopo. 
5) A demanda seguirá a heterogeneidade proposta por Valente (2012), conforme destacado em seção posterior.

6) As firmas decidem a precificação de seus produtos como uma resposta às variações de sua participação de mercado.

A estrutura básica do modelo pode ser descrita conforme o Quadro 1 abaixo. Os próximos subtópicos da seção 2 são responsáveis pelo detalhamento do ambiente da oferta e da demanda.

\section{Quadro 1}

Fluxograma dos ambientes de decisão

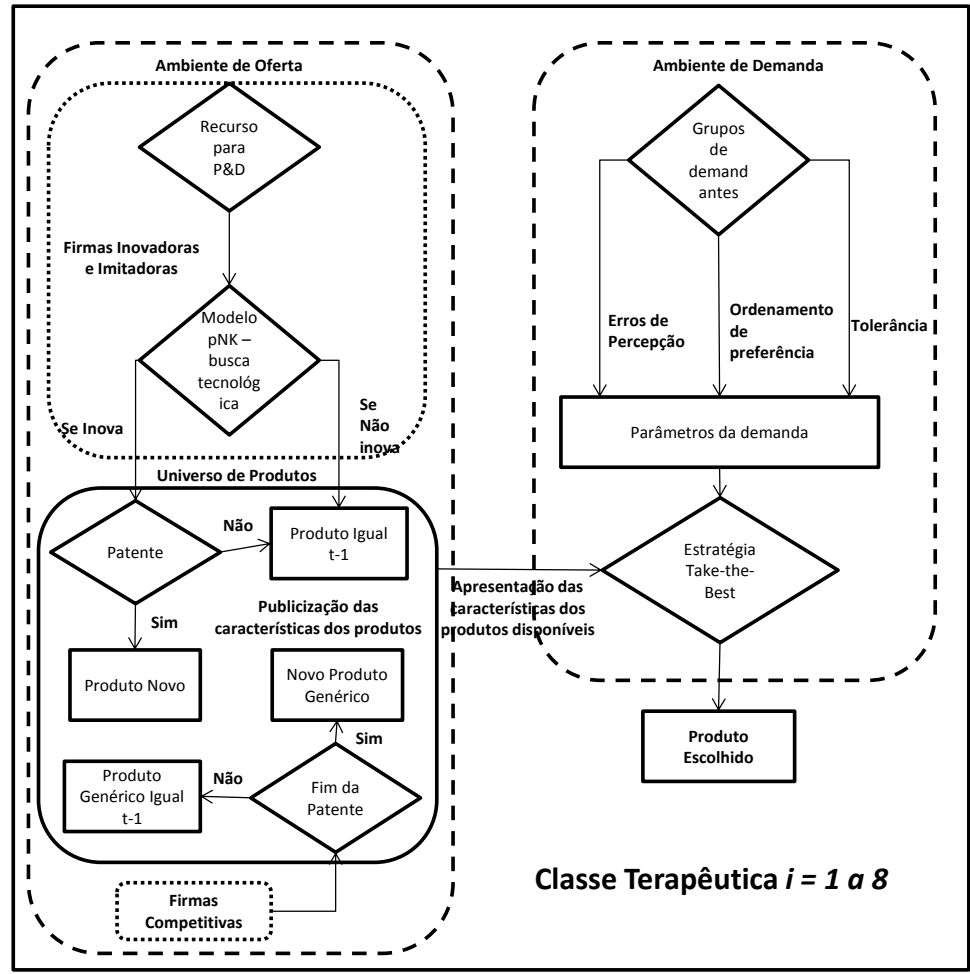

Fonte: Elaboração Própria.

\subsection{Determinantes da inovação: decisões de investimento e busca tecnológica ${ }^{8}$}

Em essência, a capacitação infraestrutural em projetos de $\mathrm{P} \& \mathrm{D}$ das empresas da indústria farmacêutica depende pouco dos resultados de mercado no curto prazo: a infraestrutura é pré-estabelecida e baseada em estratégias competitivas de longo prazo. Porém, não é verdade que a capacidade máxima será sempre utilizada. A

(8) Cabe lembrar que a decisão de investimento tecnológico e busca tecnológica cabe somente às empresas inovadoras e imitadoras. 
decisão sobre investimento em P\&D está, de alguma forma, ligada a uma análise criteriosa da evolução das variáveis financeiras, da estratégia competitiva da empresa e das mudanças na estrutura da indústria. As capacitações das firmas na realização de investimentos em inovação são distintas, simbolizadas pela diferença nos recursos financeiros disponíveis para a realização de tal empreitada.

Assim, as firmas decidem sua capacitação para realização de $\mathrm{P} \& \mathrm{D}$ de acordo com o lucro realizado no período passado (assim como em Klepper, 1996), de forma que:

$$
\text { (2.1) ResourcesRD } D_{i, t}=\Pi_{i, t-1}
$$

A variável Resources $R D_{i, t}$ é um fluxo de recursos monetários, igual ao lucro realizado pela firma no período anterior da simulação ${ }^{9}$. Essa especificação é estabelecida para as firmas inovadoras e imitadoras, visto que as firmas competitivas não terão esforço de P\&D (como será explicitado mais adiante).

A decisão de investimento via recursos disponibilizados vai impactar diretamente na quantidade de buscas tecnológicas realizadas pela firma dentro do modelo NK-like, nos mesmos moldes do modelo de Valente (2013). O modelo consiste de uma fitness function definida sobre $N$ variáveis de entrada (dimensões) e um algoritmo de busca, gerando resultados para cada ponto da dimensão (os fitness value). O fitness value de um ponto com o domínio na paisagem (landscape) é a média da contribuição fitness das $N$ dimensões:

$$
\text { (2.2) } f(\vec{x})=\frac{\sum_{i=1}^{N} \phi_{i}(\vec{x})}{N}
$$

No qual $\phi_{i}(\vec{x})$ é a contribuição para o fitness de cada dimensão tecnológica $i$, definida como uma função determinística do tipo:

$$
\text { (2.3) } \phi_{i}(\vec{x})=\frac{\operatorname{Max}}{\left(1+\left|x_{i}-\mu_{i}(\vec{x})\right|\right)}
$$

Onde Max é um parâmetro pré-determinado pelo modelador para o máximo da função. $\phi_{i}$ é, assim, uma função decrescente da distância entre o valor da variável $\left(x_{i}\right)$ e uma função $\mu_{i}(\vec{x})$, definida como:

$$
\text { (2.4) } \mu_{i}(\vec{x})=c_{i}+\sum_{j=1}^{N} a_{i, j} x_{j}
$$

Em que $c_{i}$ é uma constante definida por dimensão tecnológica e $a_{i, j}$ é a interdependência tecnológica entre as dimensões $i$ e $j$. Os valores $\mu_{i}$ definem o estabelecimento de uma meta que, quando igual a $x_{i}$, determina o maior nível de

(9) A equação do lucro total da firma será apresentada posteriormente. 
contribuição da dimensão (variável de entrada) para a fitness function global ${ }^{10}$. O algoritmo de busca através de mutações unilaterais (one-bit mutation) consiste em uma estratégia realizada nos seguintes passos:

1) Escolha randômica de uma direção;

2) Estabelecimento do valor $\Delta_{T}$ de mutação na dimensão escolhida;

3) Se o fitness value (média) aumenta e o fitness de nenhuma dimensão decresce, move-se para o novo ponto;

4) Se o fitness value (média) diminui ou o fitness de alguma dimensão decresce, continua no mesmo ponto.

As $N$ variáveis de entrada devem ser entendidas como os ingredientes compostos químicos - e/ou recursos (infraestrutura, recursos humanos, etc.) necessários para o desenvolvimento de uma nova molécula, de forma que a associação de seus valores gera um resultado médio de "qualidade" da molécula, justamente o fitness value. Pode ser entendida como o valor de determinadas características tecnológicas, como por exemplo: tempo de eficácia, reação adversa e efeito colateral.

Cada um dos ingredientes/recursos tem um valor de contribuição $\left(\phi_{i}(\vec{x})\right)$ para a "qualidade" da molécula, que é máximo em um determinado ponto, expressando a possibilidade de exaustão da fronteira tecnológica. A interdependência $a_{i, j}$ expressa a complexidade tecnológica do exercício de modelagem, definindo a dificuldade de se alcançar o máximo global do fitness value: no modelo foi definida a complexidade máxima entre a associação dos atributos tecnológicos $\left(a_{i, j}=1\right)$.

A diferenciação das empresas em relação à sua estratégia de financiamento tecnológico - ResourcesRD - define exatamente a quantidade de vezes que a firma realizará tentativas de busca tecnológica. Essa especificação remete às economias de escala tecnológica que são possíveis de serem alcançadas justamente pela melhoria do resultado de mercado: se o lucro do período passado aumenta, a quantidade de busca tecnológica realizada no período atual também aumenta.

As empresas utilizarão tais recursos para inovação para angariar novas buscas no âmbito dos ingredientes/recursos possíveis de serem analisados por cada empresa (dimensão $N$ ), e na amplitude possível da mutação $\Delta_{\mathrm{T}}$ a partir de um ponto inicial do landscape. Em relação a $N$, significa dizer que firmas escaneiam diferentes

(10) Resultados mais amplos da especificação proposta são apresentados em Valente (2008) como, por exemplo, a dependência da maximização da função a todas as dimensões. Suprimimos essas explicações aqui, mas sugerimos a leitura do texto original para leitores interessados. 
quantidades de ingredientes/recursos ao mesmo tempo. Algumas empresas têm melhor capacidade de prospectar que outras.

Estabelecem-se vinte dimensões $(N=20)$ possíveis de incremento tecnológico para as empresas. Essas dimensões definirão o fitness value com a existência de três possíveis atributos tecnológicos, a saber: tempo de eficácia, reação adversa e efeito colateral. É apresentado abaixo o Quadro 2, com a relação dos ingredientes/recursos acessados pelas empresas (NumDimRD), o valor de variação $\Delta_{\mathrm{T}}$ da mutação e a capacitação tecnológica (ResourcesRD), por grupo de empresas.

Quadro 2

Número de atributos tecnológicos acessados (dimensões pesquisadas), número de variações da mutação e capacitação tecnológica - Parametrização

\begin{tabular}{|c|c|c|c|}
\hline \multirow{2}{*}{ Grupo de Firmas } & $\begin{array}{c}\text { Dimensões } \\
\text { Pesquisadas }\end{array}$ & $\begin{array}{c}\text { Variações da } \\
\text { Mutação }\end{array}$ & $\begin{array}{c}\text { Capacitação } \\
\text { tecnológica }\end{array}$ \\
\cline { 2 - 4 } & NumDimRD & $\Delta_{\mathrm{T}}$ & Resources RD \\
\hline Imitadoras (firmas 4 a 6) & 10 & 1 & $\Pi_{i, t-1}$ \\
\hline Inovadoras (firmas 7 a 9) & 20 & 3 & $\Pi_{i, t-1}$ \\
\hline
\end{tabular}

Fonte: Elaboração própria.

Essa configuração permite que as firmas inovadoras tenham menor risco de incorrerem em um lock-in tecnológico (um ponto de ótimo local) se comparadas às empresas imitadoras. Além disso, a expectativa é permitir maiores probabilidades de estratégias de inovação radical para as firmas inovadoras e inovação incremental para firmas imitadoras.

Se uma firma inovadora ou imitadora consegue alguma inovação em algum atributo, ela agora se verá diante da possibilidade de transformar a nova molécula em um novo produto na classe terapêutica específica de busca. Para isso ela analisa (i) a comparação da melhoria em alguma característica da molécula em relação a seu portfólio e (ii) a avaliação da possibilidade de oferta, que passa necessariamente na análise das moléculas que podem ser produtos passíveis de patenteamento ou produtos que são de domínio público.

Nesse processo, a empresa segue uma verificação comum a todas as firmas (inovadoras e imitadoras, visto que competitivas não realizam busca tecnológica): analisar se pelo menos o valor de um dos atributos tecnológicos é superior a algum produto produzido pela firma. Caso isso ocorra, ela é passível de ser escolhida. Caso contrário, é rejeitada e o processo de $\mathrm{P} \& \mathrm{D}$ continua do mesmo ponto. 
A próxima fase é a verificação da possibilidade de patenteamento do produto. No modelo será estabelecido patenteamento de novos produtos às firmas inovadoras e imitadoras, mas a garantia da propriedade intelectual só é dada após uma checagem do ambiente de oferta, na busca por produtos com características próximas. É definida uma distância mínima de valor das características tecnológicas dos produtos que deve ser respeitada para não configurar que a inovação gerada pela empresa seja considerada uma cópia de produto existente. Para o modelo, a nova molécula precisa ter, em pelo menos uma característica tecnológica, um valor 5\% distante aos produtos já ofertados no mercado.

Essa distância não significa necessariamente que o produto é superior a todos os produtos ofertados no mercado. Se o produto inovador respeitar a distância no limite inferior e no limite superior, ele pode se credenciar ao patenteamento na classe terapêutica específica. Esse recurso permite a possibilidade de inovações incrementais em produtos com tecnologia ultrapassada, mas que talvez tenham uma rentabilidade elevada pela competitividade via preço.

Sendo patenteado, o novo produto terá um período de monopólio no mercado da ordem de 100 rodadas de simulação (Parametrização Inicial). Após essas rodadas, a patente expira e novos produtos com os mesmos valores de características tecnológicas poderão ser produzidos. Após o novo produto ser patenteado, a empresa estabelecerá um processo de eliminação de produtos em seu portfólio: se a mesma possui algum produto com pelo menos duas das características tecnológicas inferior, esse produto terá sua produção encerrada.

Às firmas competitivas cabe escanear o ambiente de patenteamento a cada rodada de simulação, na busca por patentes expiradas, e decidir sobre a introdução de um medicamento genérico com as mesmas características do produto anteriormente patenteado. Caso o produto com patente expirada tenha valor melhor em pelo menos uma característica tecnológica na comparação com os produtos da empresa, a firma competitiva produzirá o seu genérico.

\subsection{Condições da demanda}

A proposição aqui estabelecida segue a estratégia Take-the-best proposta em Valente (2012). Os consumidores têm a tarefa de realizar compras de forma a preencher suas necessidades em meio a uma gama de produtos alternativos com características específicas e distintas, representadas por $y_{X}^{i}$.

Os agentes observam o valor $v_{X}^{i}$, de cada característica $i$ referente ao produto $X$, em que $v_{X}^{i}$ é a observação do consumidor à característica $y_{X}^{i}$ do produto analisado. Essa observação não é perfeita na maioria das vezes, devido à informação assimétrica no histórico de competência dos consumidores. 
Os consumidores baseiam suas decisões na comparação de todos os produtos disponíveis em cada classe terapêutica em relação a uma única característica. Assim, o algoritmo requer que seja identificado apenas o melhor produto - ou melhores em relação a essa única dimensão. Para essa decisão, os consumidores realizam três passos de análise: (i) a percepção dos valores das características $\left(v_{X}^{i}\right)$, (ii) a avaliação de todos os demais produtos equivalentemente ótimos e (iii) a identificação da acessibilidade desses produtos.

No primeiro passo, é considerada a possibilidade dos consumidores terem diferentes habilidades e histórico de competência na avaliação e, devido a isso, cometerem erros na comparação entre os produtos.

$$
\text { (2.5) } \hat{v}_{X}^{i}=\operatorname{Norm}\left(y_{X}^{i}, \Delta\right)
$$

Onde $\operatorname{Norm}(\mu, \sigma)$ representa um resultado a partir de uma função aleatória normalmente distribuída, e $\Delta$ a variância da variável aleatória, que funciona como uma variável proxy para o erro de percepção, a sua ignorância sobre a qualidade do produto; quanto mais baixo o valor de $\Delta$, menores os erros de percepção de valor do produto, sendo o contrário verdade.

É considerada ainda a tolerância do consumidor na comparação das características dos produtos. Comparando as características percebidas $\hat{v}$ de dois produtos $X$ e $Y$, o modelo considera que eles são equivalentes se:

$$
\text { (2.6) } \hat{v}_{X} \approx \hat{v}_{Y} \Leftrightarrow \frac{\left|\hat{v}_{X}-\hat{v}_{Y}\right|}{\max \left(\hat{v}_{X}, \hat{v}_{Y}\right)}<\tau
$$

Em que $\tau$ é um coeficiente entre 0 e 1 . Quando $\tau=0$, qualquer mínima diferença entre os valores das características é percebida para atestar a superioridade de um produto. Em oposição, altos valores de $\tau$ indicam que até mesmo grandes diferenças são consideradas irrelevantes na escolha do consumidor, padronizando os produtos em relação àquela característica. Chamaremos esse recurso de nível de tolerância. Quando $\tau=0$ o consumidor tem tolerância baixa na comparação entre o diferencial das características, e quando $\tau=1$ o consumidor tem tolerância total nessa mesma comparação.

O terceiro passo envolve a identificação da acessibilidade de produtos. Um produto pode ser descartado de consumo por não possuir requisitos mínimos ou por existir outro produto mais apreciado pelo consumidor. Apesar do resultado igual - o produto não é vendido -, os dois casos são diferentes porque no segundo caso, se houvesse a remoção do competidor, o produto poderia se tornar viável enquanto no primeiro caso ele ainda seria inacessível. O modelo distingue os dois casos, considerando o primeiro como parte de um processo inicial de seleção de produtos viáveis e o segundo como um passo no processo decisório do agente consumidor. 
São considerados requisitos mínimos de consumo para cada produto para poderem ser considerados como produtos viáveis para compra. Formalmente, o modelo assume que cada consumidor $j$ tem um vetor de requisitos mínimos $\vec{m}_{j}=$ $\left\{m_{j}^{1}, m_{j}^{2}, \ldots, m_{j}^{m}\right\}$ para cada característica do produto. Um produto $X$ viável para consumo é aquele no qual $v_{X}^{i}>m_{j}^{i}$ para toda característica $i$. Todos os consumidores realizam uma compra por rodada, e possuem por definição uma restrição orçamentária suficiente para a alocação de recurso na compra do produto.

Na estratégia Take-the-best (TTB) a escolha de um item é feita sobre uma série de possíveis alternativas definidas em um espaço multidimensional. $\mathrm{O}$ procedimento algorítmico utilizado consiste na repetição cíclica dos passos seguintes até que a condição de saída do passo 3 seja satisfeita:

1) Considerar inicialmente todas as opções potenciais de escolha, inclusive excluindo aqueles sem as características mínimas;

2) Escolher uma característica entre as $m$ disponíveis;

3) Se um produto possui score maior que os demais, considerando a tolerância e o erro de percepção em respeito a essa característica, a escolha está feita.

4) Se a opção 3 não é satisfeita nessa comparação, e mais de uma opção tem valores similares em respeito à característica escolhida no passo 2, então são removidas as opções com valores menores e o processo reinicia a partir do passo 2.

A esse padrão de decisão serão somadas as especificidades da indústria farmacêutica, nos moldes de um modelo evolucionário History-friendly. Nessa indústria, a demanda será retratada basicamente com a presença de dois tipos de demandantes, classificados em três grupos distintos. $\mathrm{O}$ primeiro tipo de demandante - Grupo 1 - é o Governo, responsável por 25\% da demanda setorial. O segundo tipo são os demandantes finais privados, notadamente o consumo das famílias, que representam $75 \%$ da demanda total, mas que estão divididos em dois grupos de demanda diferenciados ${ }^{11}$. Nesse modelo, foram estabelecidas percentagens iguais de participação dos grupos na demanda privada $-50 \%$ da demanda privada para cada grupo.

O Quadro 3 apresenta a ordem de preferência para os diferentes grupos de indivíduos frente às características percebidas dos produtos e o número de consumidores por grupo.

(11) Os valores percentuais sobre a participação do governo e do consumo das famílias foi obtido pela extrapolação da participação de suas demandas na indústria farmacêutica, segundo a matriz de insumo-produto de 2005 disponibilizada pelo IBGE e apresentada em Ruiz et al. (2011). 
Quadro 3

Ordem de preferência na percepção das características pelo consumidor e número de indivíduos por grupo - Parametrização inicial

\begin{tabular}{|c|c|c|c|c|c|}
\hline & & $v_{1}^{i}$ & $v_{2}^{i}$ & $v_{3}^{i}$ & $v_{4}^{i}$ \\
\hline Grupo & $\mathrm{N}$ & Preço & $\begin{array}{c}\text { Tempo de } \\
\text { Eficácia }\end{array}$ & $\begin{array}{c}\text { Reação } \\
\text { Adversa }\end{array}$ & $\begin{array}{c}\text { Efeito } \\
\text { Colateral }\end{array}$ \\
\hline G1 - Governo & 250 & 1 & 4 & 2 & 3 \\
\hline G2 - Famílias decis 1 a 3 & 375 & 1 & 2 & 3 & 4 \\
\hline G3 - Famílias decis 4 a 10 & 375 & 4 & 3 & 2 & 1 \\
\hline
\end{tabular}

Fonte: Elaboração Própria.

A parametrização do número de indivíduos por grupo de demanda foi estabelecida para definir o total de mil (1000) demandantes e as percentagens definidas por tipo de demanda. Apesar da suposição da ordem de preferência nas características ser exógena, a explicação para essa definição paira sobre informações empíricas. As famílias de baixa renda têm (i) dificuldade no acesso à medicina suplementar, utilizando métodos paliativos de controle de saúde e (ii) maior sensibilidade a preço na definição de compra (Diniz et al., 2007; Garcia et al., 2013). Assim, é provável que suas características principais de preferência em relação a produtos seja, inicialmente, o preço e, após esse, o tempo de eficácia do medicamento. Pelo contrário, famílias com renda mais elevada podem estar preocupadas com a qualidade do produto no que tange a seus efeitos sobre a saúde em um contexto mais amplo, no sentido de como esses medicamentos interagem com seu organismo, estilo de vida, e saudabilidade.

O Quadro 4, abaixo, especifica a parametrização dos valores $\tau$ e $\Delta$ para os distintos grupos de consumidores na Parametrização Inicial. Essa parametrização será modificada no decorrer da análise de resultados para verificar a influência da modificação dos parâmetros de demanda nos resultados de mercado.

Quadro 4

Parâmetros $\boldsymbol{\tau}$ e $\Delta$ para os distintos grupos de consumidores - Parametrização inicial

\begin{tabular}{|c|c|c|c|c|c|}
\hline & & $v_{1}^{i}$ & $v_{2}^{i}$ & $v_{3}^{i}$ & $v_{4}^{i}$ \\
\hline \multirow{2}{*}{ Grupo } & & Preço & $\begin{array}{c}\text { Tempo de } \\
\text { Eficácia }\end{array}$ & $\begin{array}{c}\text { Reação } \\
\text { Adversa }\end{array}$ & $\begin{array}{c}\text { Efeito } \\
\text { Colateral }\end{array}$ \\
\hline \multirow{2}{*}{ G1 - Governo } & $\tau$ & 0,05 & 0,90 & 0,90 & 0,90 \\
\cline { 2 - 6 } G2 - Famílias decis 1 a 3 & $\Delta$ & 0,05 & 0,90 & 0,90 & 0,90 \\
\cline { 2 - 6 } & $\tau$ & 0,05 & 0,95 & 0,95 & 0,95 \\
\hline \multirow{2}{*}{ G3 - Famílias decis 4 a 10 } & $\tau$ & 0,05 & 0,05 & 0,05 & 0,05 \\
\cline { 2 - 6 } & $\Delta$ & 0,95 & 0,95 & 0,10 & 0,10 \\
\hline
\end{tabular}

Fonte: Elaboração Própria. 
No caso do governo, a explicação é que tal agente possui um baixo erro de percepção sobre o nível de preços $(\Delta=0,05)$, mas possui uma alta indiferença de percepção em relação às demais características $(\Delta=0,90)$. Ainda, o nível de tolerância entre produtos no diferencial de preço é baixo $(\tau=0,05)$, o que significa alta intolerância sobre diferentes preços, próximo à definição da característica principal de um processo de licitação, que é a compra do produto de menor preço ${ }^{12}$.

Famílias mais carentes - Grupo 2 - possuem baixo nível de tolerância $(\tau=$ $0,10)$ para diferenciais de preços e um nível maior de tolerância para diferenciais nas demais características $(\tau=0,95)$, com algum erro de percepção sobre as variáveis $(\Delta$ $=0,05)$. Esse grupo de demanda tem forte preferência estabelecida sobre preços, e são mais suscetíveis a tolerar as demais características dos produtos. Em relação ao erro de percepção, a indicação aqui apresentada é feita para contrastar com os erros de percepção do Grupo 3, de famílias com renda mais elevada $(\Delta=0,05$ para Grupo 2 e $\Delta=0,03$ para Grupo 3). Pretende-se apenas indicar que pessoas com maior renda monetária possuem maior grau de informação sobre os produtos disponíveis.

Ainda, famílias com renda maior - Grupo 3 - possuem baixo nível de tolerância para diferenças em relação às características "reação adversa" e "efeitos colaterais" $(\tau=0,10)$, mas possuem alto nível de tolerância para diferenciais nas características "preço" e "tempo de eficácia" $(\tau=0,95)$. Esse grupo de demanda tem forte preferência estabelecida sobre os aspectos qualitativos.

Os valores mínimos de exigência das características tecnológicas para que os produtos sejam passíveis de escolha pelos consumidores foram estabelecidas como zero, para todos os grupos de demandantes. É condizente a dizer que os indivíduos aceitam qualquer produto com valores positivos de características tecnológicas ou ainda, que passaram pelo crivo da regulação setorial (Anvisa). Para o preço, o pensamento deve ser contrário: o valor mínimo de exigência do consumidor corresponde ao mais alto preço que tal demandante está disposto a pagar pelo produto. A parametrização estabelece um valor de preço igual a quinze (15) unidades monetárias (U.M.), também para todos os grupos de demanda.

(12) A consideração do baixo nível de tolerância e baixo erro de percepção (em contrapartida a um nível de tolerância total e nenhum erro de percepção) foi utilizada para exprimir a possibilidade de algumas empresas não participarem do processo de licitação. Os parâmetros são usuais para essa representação, pois a presença de erros na percepção do consumidor Governo expressa que não necessariamente o produto com menor preço será escolhido. Se isso é verdade, pode-se argumentar que a empresa de menor preço não participou do referido processo. 


\subsection{Estratégia de precificação dos produtos}

As empresas estabelecem uma regra simples de precificação de produtos, baseada na análise da variação de suas parcelas de mercado ${ }^{13,14}$. A firma, porém, só estabelecerá variação em seus preços se a seguinte desigualdade ocorrer:

$$
\text { (2.7) } m s_{i, t}^{j}-m s_{i, t-1}^{j}>f
$$

Sendo $f$ um valor determinado exogenamente ${ }^{15}$ e $m s_{i, t}^{j}$ a participação de mercado do produto da empresa $i$ no período $t$ na classe terapêutica $j$. Fundamentalmente, se a desigualdade acima ocorre, a regra de precificação é a que segue.

$$
\text { (2.8) } p_{i, t}^{j}=p_{i, t-1}^{j} \cdot\left[1+s c .\left(\operatorname{sign}_{i}\right)\right]
$$

Em que $s c$ é uma constante exógena que define a magnitude de mudança de preço definida pela empresa $i^{16}$ e sign é o sinal de mudança de preço, definido pela seguinte equação.

$$
\text { (2.9) } \operatorname{sign}_{t, i}=\frac{\left|m s_{i, t}^{j}-m s_{i, t-1}^{j}\right|}{m s_{i, t}^{j}-m s_{i, t-1}^{j}}
$$

Se $m s_{i, t}^{j}>m s_{i, t-1}^{j}$, então a variável apresenta o valor sign $=1$, e a variação de preços do produto ofertado pela firma $i$ será positivo (sendo o oposto verdadeiro). Deve-se notar que a formulação apresentada pode estabelecer soluções de canto que seriam sobremaneira insatisfatórias para a análise. Pensando nisso, introduzem-se relações de valores mínimos estabelecidos para preço e participação de mercado por parte das empresas, na forma que segue:

$$
\begin{gathered}
\text { se } m s_{i, t}^{j}<\min M S \\
\text { (2.10) } p_{i, t}^{j}=p_{i, t-1 \cdot}^{j}(1-s c) \\
\text { se } p_{i, t}^{j}<\min P \\
\text { (2.11) } p_{i, t}^{j}=\min P
\end{gathered}
$$

(13) A utilização da parcela de mercado para a definição do preço da firma envolve o pleno conhecimento do agente industrial em relação à oferta de todas as firmas do mercado. Em um modelo onde a demanda a cada período variasse, essa afirmação seria pouco razoável no contexto de racionalidade limitada dos agentes. Esse não é o problema aqui: como a demanda é dada (não varia a cada período), a participação de mercado corresponde à quantidade vendida da firma. A decisão do preço é, portanto, uma decisão tomada a partir do conjunto de informação individual, em consonância com a racionalidade limitada aqui defendida.

(14) A precificação segue a mesma proposição do modelo teórico estabelecido em Caliari, Ruiz, \& Valente (2017). A ideia é estabelecer entre as empresas uma competição constante por fatias de mercado, considerando a importância da escala para esse tipo de indústria.

(15) Para as simulações do artigo foi estabelecido que há variação no preço para variação no market share acima de $1 \%(y=0.01)$.

(16) Estabelecida como $s c=0.02$ para todas as análises. 
Em que minMS é igual à participação de mercado mínima definida pela empresa para se manter no mercado (padronizado como 0.01 , ou $1 \%$, para todas as empresas) e minP é o preço mínimo praticado, podendo ser entendido como o preço de concorrência perfeita, que iguala ao custo unitário de produção (que será denominado como $c_{i}$ ). Em relação ao mínimo preço, são estabelecidos valores diferentes para os diferentes tipos de empresas, como forma de explicitar exogenamente as diferenças dos custos que recaem sobre as empresas que inovam (custos de Pesquisa e desenvolvimento, de adequação ao processo produtivo, de promoção e marketing) e os custos das empresas produtoras de medicamentos genéricos. Assim, foi estabelecido um valor 50\% inferior para os custos das empresas competitivas em relação aos custos das empresas inovadoras e imitadoras (1,0 unidade monetária e 1,50 unidade monetária, respectivamente $)^{17}$.

O preço dos produtos no início da simulação é parametrizado para 4 unidades monetárias (U.M.) para empresas inovadoras e imitadoras e 2,6 U.M. para empresas competitivas, como uma forma também de expressar exogenamente a diferença de preço que é recomendada pelo legislador entre medicamentos de marca e medicamentos genéricos ${ }^{18}$. Quando um novo produto é introduzido no mercado, ele segue a mesma precificação para o início da simulação (4 U.M. para produtos inovadores e 2,6 U.M. para produtos genéricos).

\subsection{Participação de mercado}

A participação de mercado de cada empresa $i$ na classe terapêutica $j$ é definida por:

$$
\text { (2.12) } m s_{i, t}^{j}=\frac{\sum_{i=1}^{N_{i}} q_{i, t}^{j}}{\sum_{k=1}^{N_{k}} q_{k, t}^{j}}
$$

Em que $\sum_{i=1}^{N_{i}} q_{i, t}^{j}$ é a somatória da quantidade demandada da firma $i$ na classe terapêutica $j$ no período $t$ e $\sum_{k=1}^{N_{k}} q_{k, t}^{j}$ é o somatório das vendas de todas as firmas na classe terapêutica $j$ no período $t$. Note que o formato do modelo define que cada firma poderá ofertar mais de um produto em cada classe terapêutica. Assim, a participação de mercado da firma em cada classe terapêutica é o somatório dos produtos ofertados pela mesma nessa classe terapêutica de análise.

Ademais, será verificada também a participação de mercado de cada firma na indústria em geral, através da equação que segue:

(17) Deve-se atentar que a estratégia de custos aqui apresentada corresponde a uma simplificação forte em relação aos diferenciais de custos encontrados em setores com grande diferenciação de escala e escopo industrial, principalmente no que concerne aos custos de P\&D.

(18) A indicação do Ministério da Saúde e da Anvisa é a de que o preço de entrada dos genéricos no mercado seja $35 \%$ inferior ao preço do medicamento ao qual ele se refere. 


\subsection{Receita de vendas e lucro}

$$
\text { (2.13) } m s_{i, t}=\sum_{j=1}^{N_{j}} m s_{i, t}^{j}
$$

A receita da firma $i$ na classe terapêutica $j$ no período $t$ (revenue $e_{i, t}^{j}$ ) é dada por:

$$
\text { (2.14) } \operatorname{revenue}_{i, t}^{j}=\sum_{k=1}^{N_{k}} p_{i, t, k}^{j} \cdot q_{i, t, k}^{j}
$$

Em que $p_{i, t, k}^{j}$ e $q_{i, t, k}^{j}$ são, respectivamente, o preço e a quantidade demandada do produto $k$ da firma $i$ na classe terapêutica $j$ no período $t$. Já o lucro da firma $i$ na classe terapêutica $j$ no período $t\left(\pi_{i, t}^{j}\right)$ é dado por:

$$
\text { (2.15) } \pi_{i, t}^{j}=\sum_{k=1}^{N_{k}} p_{i, t, k}^{j} \cdot q_{i, t, k}^{j}-\sum_{k=1}^{N_{k}} c_{i} \cdot q_{i, t, k}^{j}
$$

Sendo $c_{i}$ o custo unitário de produção da firma $i$, julgado constante e igual a 1.0 para as firmas competitivas e 1.5 para as firmas inovadoras e imitadoras.

É considerado não existir estoque. Tudo que é produzido é vendido ou é totalmente depreciado. Essa talvez seja uma suposição forte, que deverá ser mais bem desenvolvida posteriormente, mas para o momento funciona para delimitar o foco da análise.

\section{Resultados do modelo}

Inicialmente, são apresentados os resultados de participação de mercado e concentração industrial para toda a indústria - considerando a concorrência nas 8 classes terapêuticas - em comparação com classes terapêuticas selecionadas, como forma de corroborar o modelo comparando-o às observações dos modelos HistoryFriendly de Malerba e Orsenigo (2002) e Garavaglia et al. (2012). Os resultados iniciais são baseados na Parametrização Inicial apresentada nos subtópicos anteriores e, quando modificados, serão oportunamente informados aos leitores. Serão apresentadas quatrocentas (400) rodadas de simulação para todas as análises. O programa utilizado para a confecção do modelo e apresentação dos resultados é o Laboratory for Simulation Development (LSD).

Apesar da intensa atividade em P\&D frequentemente associada à indústria farmacêutica, os resultados empíricos apontam para baixos índices de concentração industrial. Conforme justificado em Malerba e Orsenigo (2002) e Garavaglia et al. (2012), os padrões de imitação, a natureza aleatória e baixa cumulatividade tecnológica do processo de descoberta de novas drogas e a fragmentação em vários mercados - as distintas classes terapêuticas - corroboram esse resultado. 
A Figura 1 abaixo apresenta essa constatação, ao comparar o índice $\mathrm{HH}$ da indústria farmacêutica com o índice de quatro classes terapêuticas selecionadas. Os resultados apontam para as diferenças na concentração de mercado entre a indústria geral e as classes terapêuticas, assim como observado nos trabalhos anteriormente descritos nessa seção.

\section{Figura 1}

Comparação do Índice Hirschman-Herfindahl (HH) na indústria farmacêutica e quatro classes terapêuticas - Parametrização inicial

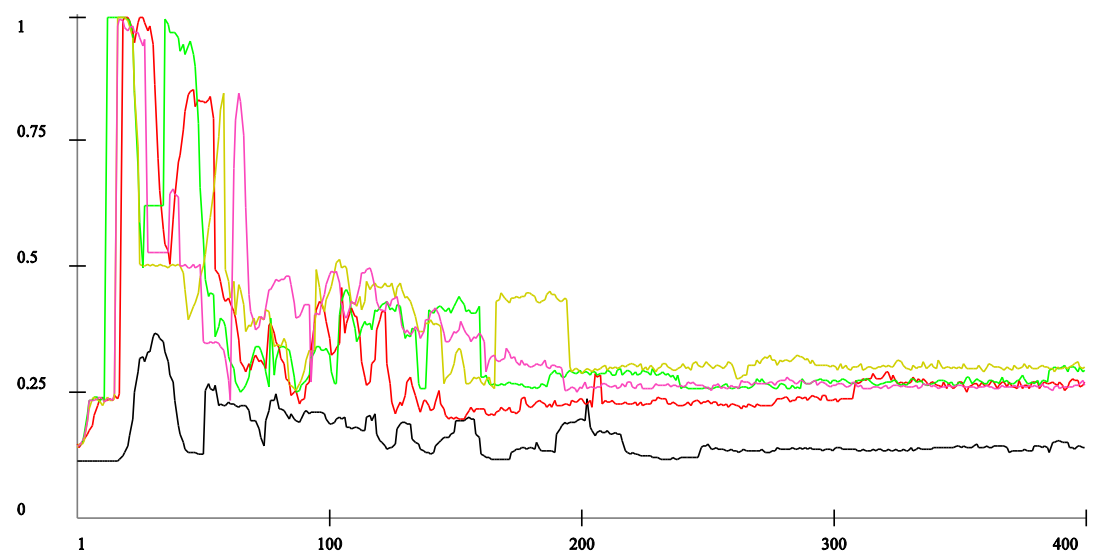

Legenda: Indústria Farmacêutica / Classe 1 / Classe 2 / Classe 3 / Classe 4.

Fonte: Elaboração própria.

Adiante são apresentados resultados para as primeiras quatro classes terapêuticas do modelo. A apresentação plena desses diferentes mercados seria contraproducente pois, como veremos, os padrões concorrenciais serão replicados. Assim, segue abaixo a Figura 2 com a apresentação da participação de mercado das empresas e a Figura 3 com o índice Hirschman-Herfindahl $(\mathrm{HH})$ de concentração industrial. Relembrando, as firmas 1 a 3 são produtoras de medicamentos genéricos, as firmas 4 a 6 são firmas imitadoras e as firmas 7 a 9 são inovadoras. 
Figura 2

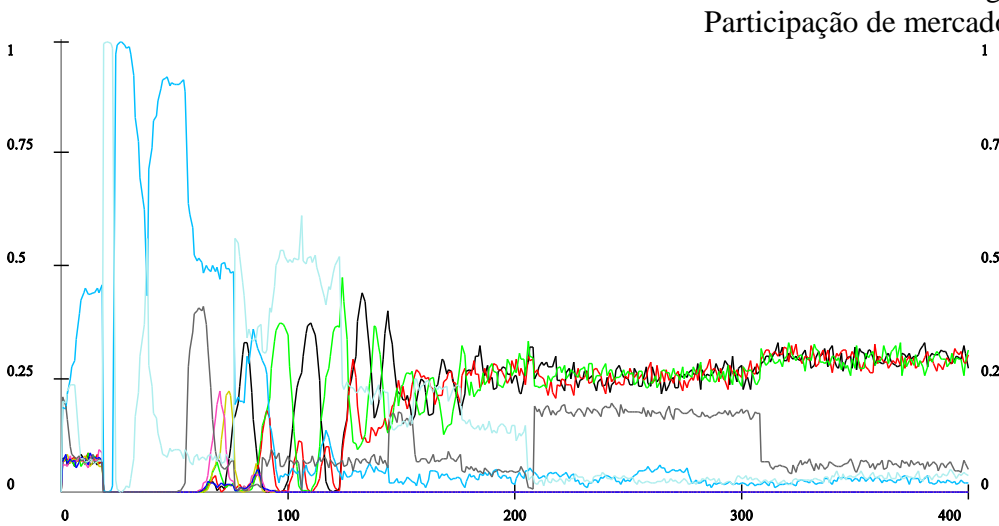

Parametrização inicial
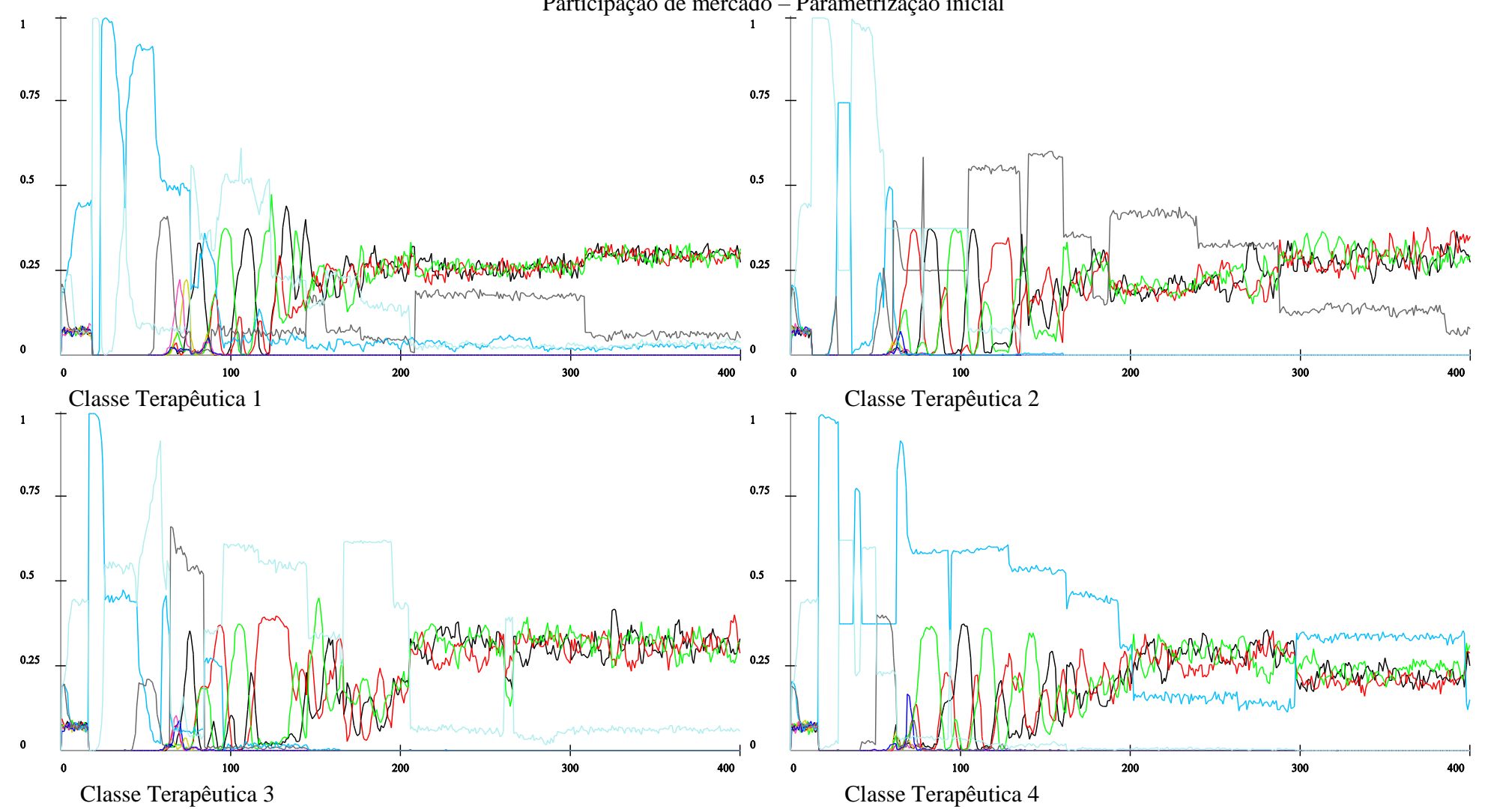

Classe Terapêutica 2

Legenda: Firma 1 / Firma 2 / Firma 3 / Firma 4 / Firma 5 / Firma 6 / Firma 7 / Firma 8 / Firma 9. Fonte: Elaboração própria. 


$$
\text { Figura } 3
$$

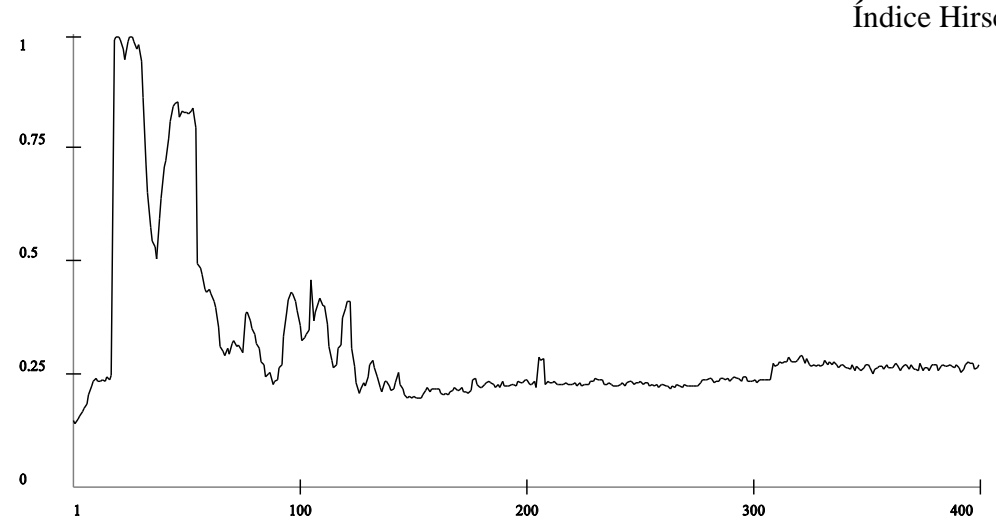

(HH) - Parametrização inicial

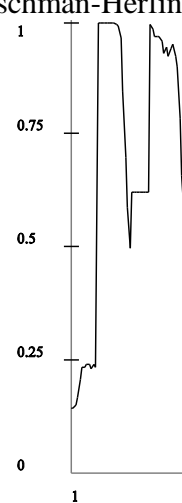

Classe Terapêutica 1
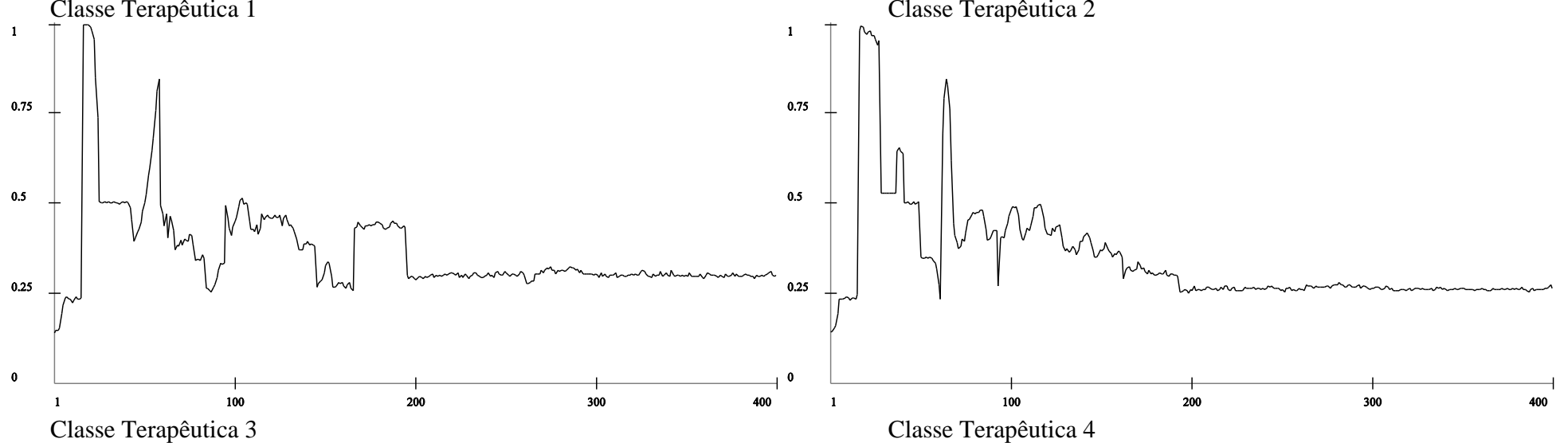

Fonte: Elaboração própria 
Da análise das quatro classes terapêuticas apresentadas emergem algumas características que são de importante destaque. A primeira delas é a replicação do modelo a análises empíricas de estudos de ciclo de vida industrial (Mazzucato, 1998), e dos regimes tecnológicos conforme estudos evolucionários (Nelson; Winter, 1982, dentre outros $)^{19}$.

Nas figuras, nota-se uma instabilidade de participação de mercado e concentração industrial para todas as classes terapêuticas durante os estágios iniciais da simulação, condizente com o regime tecnológico empreendedor da teoria evolucionária. O argumento geral que remete a essa constatação é a incerteza sobre produtos e mercados e a baixa base de conhecimento adquirida no nível industrial em geral. Nesse caso, a possibilidade de deflagração de liderança industrial por qualquer uma das firmas operantes no mercado é grande e possível a todas, principalmente ao se considerar a diferenciação que esta pode imprimir quando da promulgação de uma inovação.

É exatamente esse expediente que ocorre nos mercados simulados. Empresas inovadoras estabelecem liderança instável nos primeiros períodos justamente porque a base de conhecimento industrial ainda é fraca. Como estas são empresas que possuem maior capacidade inovativa, conseguem deflagrar um maior número de inovações que as posicionam como líderes de mercado para os períodos posteriores.

Klepper (1996) e Klepper e Simons (1997) ainda destacam a importância do tamanho da firma e da vantagem de ser a primeira na promulgação de inovação: segundo os autores, tais vantagens no processo de P\&D provocam um aumento do potencial inovativo e participação de mercado ao longo do tempo e limitam a participação de empresas menores.

$\mathrm{O}$ argumento sobre o ciclo de vida da indústria ainda enuncia que ao atingir um certo grau de maturidade o comportamento estrutural torna-se mais estável, com relevância das economias de escala e do comportamento path-dependence da inovação, favorecendo firmas inovadoras. Em nossa simulação, a estabilidade de mercado também é replicada no estágio industrial de maturidade, mas nesse caso não há favorecimento das firmas mais inovadoras.

Esse resultado específico remonta justamente à possibilidade de oferta de medicamentos genéricos. A permissão de cópia dos medicamentos inovadores exaure as economias de escala tecnológica e a relevância da inovação no resultado de mercado, justamente porque às empresas competitivas é permitida a produção de

(19) Estudos empíricos de ciclos de vida industriais que apresentam essa replicação podem ser encontrados nos textos de Abernathy e Utterback (1978), Acs e Audretch (1987), Audretch (1995) e Klepper (1996), além da replicação modelística no próprio texto de Mazzucato (1998). 
um produto com mesmas características e, por suposição regulatória, menores preços.

Para validação dessa afirmação e outras comparações, são apresentados resultados em relação a indicadores financeiros, econômicos e tecnológicos dos diferentes tipos de empresas. Optou-se por definir uma formalização padrão para as tabelas com a análise dos resultados para os dois distintos estágios do ciclo de vida da indústria, a saber: "estágio inicial" e "estágio maturidade". A metodologia sugerida para tal diferenciação é definida pelo momento no qual o índice $\mathrm{HH}$ apresenta estabilidade. Esse intervalo de períodos será apresentado entre parênteses, logo após o nome do estágio. Os resultados apresentados são a média para o conjunto das oito (8) classes terapêuticas estabelecidas na análise.

Tabela 1

Indicadores econômicos, financeiros e de tecnologia da indústria farmacêutica Parametrização inicial (média das classes terapêuticas)

\begin{tabular}{l|c|c|c|c|c|c}
\hline \multirow{2}{*}{ Firmas } & \multicolumn{3}{|c|}{ Estágio Inicial (0-182) } & \multicolumn{3}{c}{ Estágio Maturidade (183-400) } \\
\cline { 2 - 7 } & Inovadoras & Imitadoras & Competitivas & Inovadoras & Imitadoras & Competitivas \\
\hline $\begin{array}{l}\text { Receita vendas } \\
\text { média }\end{array}$ & 458,52 & 180,82 & 208,06 & 356,92 & 154,21 & 1165,84 \\
\hline Lucro médio & 79,20 & 14,67 & 27,75 & 4,91 & 0,01 & 43,74 \\
\hline Preço médio & 1,86 & 1,78 & 1,72 & 1,54 & 1,58 & 1,20 \\
\hline $\begin{array}{l}\text { Número de } \\
\text { produtos médio }\end{array}$ & 1,32 & 1,00 & 1,89 & 1,42 & 1,00 & 4,29 \\
\hline $\begin{array}{l}\text { Receita vendas } \\
\text { média / produto }\end{array}$ & 347,36 & 180,82 & 110,08 & 251,35 & 154,21 & 271,76 \\
\hline $\begin{array}{l}\text { Lucro médio / } \\
\text { produto }\end{array}$ & 60,00 & 14,67 & 14,68 & 3,46 & 0,01 & 10,20 \\
\hline $\begin{array}{l}\text { Número médio } \\
\text { de Patentes }\end{array}$ & \multicolumn{7}{|c|}{8} & & 4 & \\
\hline
\end{tabular}

Nota: O número médio de patentes é estabelecido para todo o mercado, não sendo diferenciado por tipo de empresa.

Fonte: Elaboração própria.

A diminuição da participação de mercado das inovadoras, com a ascensão das empresas produtoras de medicamentos genéricos, é acompanhada pela erosão dos lucros das primeiras, em detrimento do aumento do lucro das últimas. Aliás, é essa diminuição do lucro que diminui o ímpeto inovativo das empresas inovadoras, pois a diminuição da lucratividade total da firma inovadora diminui a própria capacitação na realização de pesquisa e desenvolvimento para novos produtos. Se tal empresa possui infraestrutura e rede de relacionamentos relevante, que permita que obtenham vantagens em capacidade instalada para a realização de $\mathrm{P} \& \mathrm{D}$, a drástica diminuição de lucratividade aqui verificada impede a utilização desses recursos. 
Podem-se pontuar os seguintes resultados pela tabela descrita acima:

1) Queda da receita e da lucratividade médias das firmas inovadoras e imitadoras nos dois estágios de operação, a despeito do aumento da receita e da lucratividade médias das firmas competitivas, decorrente dos custos mais elevados para a fabricação do produto e da exaustão da fronteira tecnológica;

2) Os preços, como esperado, são maiores no estágio inicial, e apresentam tendência de queda no estágio maturidade. Não atingem, porém, o custo unitário de produção, o que garante a rentabilidade acima do lucro normal para as empresas, notadamente as competitivas;

3) Aumento considerável no número de medicamentos oferecidos pelas empresas competitivas: o alto grau de inovação e consequente patenteamento de produtos realizados no estágio inicial permitem às empresas competitivas a inserção de maior quantidade de medicamentos genéricos no estágio de maturidade da indústria, comportamento típico na indústria farmacêutica;

4) Esse aumento de portfólio reduz o lucro médio por produtos, mas permite que tal lucratividade seja superior à alcançada pelas firmas inovadoras;

5) Redução do número médio de patentes depositadas, resultado este que é diretamente relacionado, em um primeiro momento, à queda de lucratividade das firmas inovadoras e imitadoras e, no segundo momento, à exaustão da fronteira tecnológica.

Notícias veiculadas na mídia permitem avaliar o resultado modelístico à luz da realidade empírica. Em 2012, o lucro da Sanofi-Aventis recuou 62\%; no primeiro semestre de 2013, os lucros da Merck e Bristol-Myers caíram 49\% e 17\%, respectivamente (Valor Econômico, 2013). Além disso, no período entre 2012 e 2016, os lucros da Roche caíram 65\%. Todas essas empresas são multinacionais com forte atuação em medicamentos de marca, líderes mundiais na indústria farmacêutica e com estratégias de P\&D bem estabelecidas. E, apesar da redução do lucro não estar somente associada aos fatores aqui implicitamente considerados, ela impacta diretamente no potencial de geração de inovações (no modelo isso pode ser visto na redução do número médio de patentes depositadas). Para dirimir essa questão, as empresas multinacionais (as principais empresas inovadoras) vêm buscando novas estratégias para desenvolvimento de novos produtos, como projetos de cofinanciamento e de partilhas de risco: a Merck tem procurado investidores externos para financiamento de seus ensaios clínicos, a Eli Lilly tem explorado iniciativas de partilha de custos, a AstraZeneca e a MSD co-desenvolveram uma terapia para a diabetes, enquanto a GlaxoSmithKline e a Pfizer criaram conjuntamente uma joint venture focada em tratamentos contra o HIV. Outra estratégia é a modificação de conduta competitiva com foco mais próximo a uma maior aproximação da 
concorrência via genéricos, como pode ser avaliado nos processos de F\&A da Sanofi-Aventis e Medley e da Pfizer e Teuto Farmacêutica (Cade, 2009, 2010).

\subsection{Modificações na preferência dos consumidores e o impacto nos resultados de mercado}

O objetivo das subseções abaixo é observar mudanças nos parâmetros dos consumidores e como essas impactam os resultados das empresas no modelo. Será visto que as diferentes especificações da demanda provocam mudanças consideráveis na estrutura e desempenho das empresas no ambiente industrial.

\subsubsection{O poder de compra do Estado: mudança das características de escolha do demandante governo}

Inicialmente, supõe-se na próxima análise a modificação do padrão de escolha do governo nos moldes do Decreto 7.713 (Brasil, 2012), que estabelece margens de preferência para a compra governamental de fármacos e medicamentos até um teto de $25 \%$ a mais no preço de compra, resguardadas determinadas especificidades que as empresas têm que cumprir para serem elegíveis ao processo de licitação. A questão a ser classificada aqui, certamente com uma visão mais radical, é a seguinte: e se o processo de escolha do governo fosse pautado com base na análise de variáveis tecnológicas, sendo o preço um padrão de escolha de balizamento secundário?

Para analisar esse aspecto, é importante a inversão do ordenamento de preferência do Governo, para um padrão de decisão pautado agora na análise preferencial das características tecnológicas, como descrito no Quadro 5.

Quadro 5

Ordem de preferência e parâmetros $\boldsymbol{\tau}$ e $\Delta$ para o consumidor governo - parametrização inicial e parametrização governo $(*)$

\begin{tabular}{|l|c|c|c|c|c|}
\hline \multirow{2}{*}{ Grupo } & & $v_{1}^{i}$ & $v_{2}^{i}$ & $v_{3}^{i}$ & $v_{4}^{i}$ \\
\cline { 2 - 6 } & $\mathrm{N}$ & Preço & $\begin{array}{c}\text { Tempo de } \\
\text { Eficácia }\end{array}$ & $\begin{array}{c}\text { Reação } \\
\text { Adversa }\end{array}$ & $\begin{array}{c}\text { Efeito } \\
\text { Colateral }\end{array}$ \\
\hline Parametrização Inicial & 250 & 1 & 4 & 2 & 3 \\
\hline \multirow{2}{*}{ G1 - Governo } & $\tau$ & 0,05 & 0,90 & 0,90 & 0,90 \\
\hline Parametrização Governo & $\Delta$ & 0,05 & 0,90 & 0,90 & 0,90 \\
\hline \multirow{2}{*}{ G1 - Governo } & 250 & 4 & 3 & 2 & 1 \\
\cline { 2 - 6 } & $\Delta$ & 0,05 & 0,05 & 0,05 & 0,05 \\
\hline
\end{tabular}

(*) Para estabelecer um padrão para o entendimento do estudo de impacto de mudanças nos parâmetros, serão apresentadas em cada subtópico as modificações realizadas em relação à Parametrização Inicial. Sendo assim, todos os demais parâmetros que não são discutidos nas referidas subseções continuam com os valores da Parametrização Inicial.

Fonte: Elaboração própria. 
Essa nova formatação modifica dois aspectos fundamentais do comportamento do consumidor Governo: sua relação de preferências e também o conhecimento sobre os produtos disponíveis para compra. Agora é suposto que, além de escolher de maneira diferente - tecnológica em relação a preço -, o governo tem maior conhecimento (ou pelo menos o utiliza agora, se considerarmos que ele já possuía esse conhecimento) da qualidade dos produtos, podendo estabelecer sua decisão de compra com maior nível de informações. Deve ser entendido que essa modificação no acesso à informação, somada à modificação na ordenação de preferências, tendem a trabalhar em conjunção para modificar os resultados de mercado em prol de melhores resultados inovativos. A apresentação da Tabela 2 corrobora essa suposição e fornece maiores evidências e informações para o argumento.

Tabela 2

Indicadores econômicos, financeiros e de tecnologia da indústria farmacêutica Parametrização governo (média das classes terapêuticas)

\begin{tabular}{l|c|c|c|c|c|c}
\hline \multirow{2}{*}{ Firmas } & \multicolumn{3}{|c|}{ Estágio Inicial (0-250) } & \multicolumn{3}{c}{ Estágio Maturidade (251-400) } \\
\cline { 2 - 7 } & Inovadoras & Imitadoras & Competitivas & Inovadoras & Imitadoras & Competitivas \\
\hline Receita vendas média & $+46 \%$ & $+3 \%$ & $+52 \%$ & $-50 \%$ & $+202 \%$ & $+61 \%$ \\
\hline Lucro médio & $+11 \%$ & $+125 \%$ & $+318 \%$ & $-8 \%$ & $+202 \%$ & $+153 \%$ \\
\hline Preço médio & $-3 \%$ & $+3 \%$ & $+12 \%$ & $+7 \%$ & $+9 \%$ & $+38 \%$ \\
\hline Número de produtos médio & $-5 \%$ & $0 \%$ & $+56 \%$ & $+22 \%$ & $0 \%$ & $+82 \%$ \\
\hline $\begin{array}{l}\text { Receita vendas média / } \\
\text { produto }\end{array}$ & $+53 \%$ & $+3 \%$ & $-38 \%$ & $-59 \%$ & $+202 \%$ & $-11 \%$ \\
\hline Lucro médio / produto & $+16 \%$ & $+125 \%$ & $+168 \%$ & $-24 \%$ & $+202 \%$ & $+39 \%$ \\
\hline Número médio de Patentes & \multicolumn{7}{|c|}{$+13 \%$} & & & $+25 \%$ & \\
\hline
\end{tabular}

Nota: O número médio de patentes é estabelecido para todo o mercado, não sendo diferenciado por tipo de empresa.

Fonte: Elaboração própria.

A análise percentual sugerida na tabela deve ser feita em relação à Tabela 1 , que apresenta os valores da Parametrização Inicial. Assim, por exemplo, o resultado de $+46 \%$ para a receita média de vendas das firmas inovadoras no estágio inicial significa que, para essa variável, o resultado foi $46 \%$ maior na Parametrização Governo do que na Parametrização Inicial.

Depreendem-se da análise da tabela algumas importantes constatações:

1) Melhoria nos resultados financeiros das empresas imitadoras, principalmente no estágio de maturidade da indústria. Essas conseguiram alcançar maiores participações de mercado e melhores indicadores financeiros em detrimento, principalmente, da redução de relevância das empresas inovadoras; 
2) Apesar disso, no estágio inicial da indústria, as firmas inovadoras também obtiveram importante melhoria de indicadores (46\% sobre receita média de vendas e $11 \%$ sobre lucro), e o resultado conjunto dessas e das firmas imitadoras foram importantes para o acréscimo na quantidade de patentes depositadas: tal incremento foi de $13 \%$ e $25 \%$ nos estágios inicial e maturidade, respectivamente;

3) $\mathrm{O}$ resultado sobre os preços é um aumento considerável em relação à Parametrização Inicial, da ordem média de $22 \%$. Esse resultado acontece pois agora há uma relevância maior para as características tecnológicas em detrimento do preço. Mesmo assim, as empresas que mais se beneficiaram desse novo padrão de compra foram as empresas competitivas, visto que conseguem mimetizar a tecnologia dos concorrentes após a expiração das patentes. Explica-se: a concorrência via preços é menor na configuração dessa parametrização pela relevância das características tecnológicas no processo de compra. Sendo assim, a tendência de queda dos preços com a introdução dos genéricos é minorada. Como as empresas estarão oferecendo produtos com as mesmas características (pela exaustão da fronteira tecnológica), as empresas competitivas obtêm vantagem concorrencial;

As observações pontuadas - e outras que se possam fazer - demonstram que a desconsideração do impacto de modificações na demanda em mercados com alto índice tecnológico pode viesar os resultados da dinâmica estrutural, de conduta e desempenho das empresas de maneira considerável.

\subsubsection{A relevância da inovação incremental: mudança das características de escolha do demandante Grupo 3}

Suponha agora que, dado o sucesso da política de genéricos, o padrão de compra dos demandantes do Grupo 3 (classe de renda superior) possa sofrer alterações. Nesse novo cenário, a credibilidade dos testes de bioequivalência e o aumento da participação de mercado das empresas competitivas ajudam na reavaliação das características exigidas por esses tipos de consumidores, de forma que tais agentes possam se encontrar mais propensos a aceitar produtos com menores preços, dado que entendem e aceitam que as características tecnológicas desses produtos mais baratos são iguais às do produto de marca. Essa nova ordenação dos consumidores do Grupo 3 pode ser expressa conforme o Quadro 6. 
Quadro 6

Ordem de preferência e parâmetros $\boldsymbol{\tau}$ e $\Delta$ para o consumidor Grupo 3 -

Parametrização inicial e parametrização Grupo 3

\begin{tabular}{|c|c|c|c|c|c|}
\hline & & $v_{1}^{i}$ & $v_{2}^{i}$ & $v_{3}^{i}$ & $v_{4}^{i}$ \\
\hline Grupo & $\mathrm{N}$ & Preço & $\begin{array}{c}\text { Tempo de } \\
\text { Eficácia }\end{array}$ & $\begin{array}{c}\text { Reação } \\
\text { Adversa }\end{array}$ & $\begin{array}{c}\text { Efeito } \\
\text { Colateral }\end{array}$ \\
\hline Parametrização Inicial & 375 & 4 & 3 & 2 & 1 \\
\hline \multirow{2}{*}{ G3 - Famílias decis 4 a 10 } & $\tau$ & 0,95 & 0,95 & 0,10 & 0,10 \\
\cline { 2 - 6 } & $\Delta$ & 0,03 & 0,03 & 0,03 & 0,03 \\
\hline Parametrização Grupo 3 & 375 & 1 & 4 & 3 & 2 \\
\hline \multirow{2}{*}{ G3 - Famílias decis 4 a 10 } & $\tau$ & 0,10 & 0,10 & 0,10 & 0,10 \\
\cline { 2 - 6 } & $\Delta$ & 0,03 & 0,03 & 0,03 & 0,03 \\
\hline
\end{tabular}

Fonte: Elaboração própria.

As suposições descritas acima equivalem a definir uma reordenação da ordem de preferência, onde o preço teria uma consideração mais relevante do que na Parametrização Inicial. Indica-se aqui que o preço passa a ser a primeira preferência no processo de ordenação dos agentes dessa classe. Os resultados comparativos à parametrização inicial são vistos na tabela abaixo.

Tabela 3

Indicadores econômicos, financeiros e de tecnologia da indústria farmacêutica Parametrização Grupo 3 (média das classes terapêuticas)

\begin{tabular}{l|c|c|c|c|c|c}
\hline \multirow{2}{*}{ Firmas } & \multicolumn{3}{|c|}{ Estágio Inicial (0-178) } & \multicolumn{3}{c}{ Estágio Maturidade (179-400) } \\
\cline { 2 - 7 } & Inovadoras & Imitadoras & Competitivas & Inovadoras & Imitadoras & Competitivas \\
\hline $\begin{array}{l}\text { Receita vendas } \\
\text { média }\end{array}$ & $-13 \%$ & $+9 \%$ & $+76 \%$ & $+14 \%$ & $+6637 \%$ & $-25 \%$ \\
\hline $\begin{array}{l}\text { Lucro médio } \\
\text { Ireço médio }\end{array}$ & $-26 \%$ & $+230 \%$ & $+710 \%$ & $+200 \%$ & $+222 \%$ & $+478 \%$ \\
\hline $\begin{array}{l}\text { Número de produtos } \\
\text { médio }\end{array}$ & $+22 \%$ & $+12 \%$ & $+28 \%$ & $+14 \%$ & $+2 \%$ & $+69 \%$ \\
\hline $\begin{array}{l}\text { Receita vendas } \\
\text { média / produto }\end{array}$ & $-29 \%$ & $+9 \%$ & $+11 \%$ & $-31 \%$ & $+6637 \%$ & $-33 \%$ \\
\hline $\begin{array}{l}\text { Lucro médio / } \\
\text { produto }\end{array}$ & $-39 \%$ & $+230 \%$ & $+410 \%$ & $+82 \%$ & $+22 \%$ & $+42 \%$ \\
\hline $\begin{array}{l}\text { Número médio de } \\
\text { Patentes }\end{array}$ & $+13 \%$ & $+59 \%$ & $+65 \%$ & $0 \%$ & $+11 \%$ \\
\hline
\end{tabular}

Fonte: Elaboração própria.

Nota: O número médio de patentes é estabelecido para todo o mercado, não sendo diferenciado por tipo de empresa. 
Apesar da mudança de preferência dos consumidores do Grupo 3 ser balizada no aumento da importância da característica preço, criou-se um ambiente mais propício à inovação, notadamente com o aumento da participação das empresas imitadoras na participação de mercado: nas quatro classes terapêuticas, o aumento médio de participação das empresas imitadoras foi da ordem de $21 \%$. Esse processo acabou por suscitar também maior instabilidade e menor concentração de mercado, com um comportamento mais dinâmico das inovações (aumento de 17\% no patenteamento total).

Apesar de ser contraintuitivo à primeira vista, dado que poderia se imaginar uma maior concentração de mercado em prol das empresas competitivas (visto o novo balizamento da preferência do Grupo 3 primeiramente pelo preço dos produtos), a nova configuração deve ser entendida à luz não apenas da mudança na ordem de preferências, mas também através do entendimento dos parâmetros que estabelecem o nível de conhecimento e tolerância dos agentes nesse mercado. Apesar dos consumidores do grupo 3 serem homogêneos em relação à ordem de preferência das características na comparação ao Grupo 2 (famílias de baixa renda) - ambos escolhem primeiro via preço -, são heterogêneos em relação à tolerância das características, pois os consumidores do grupo 3 estabelecem uma preferência pautada fortemente por melhores produtos $(\tau=0,10)$.

As empresas imitadoras conseguem galgar uma maior participação no mercado nas primeiras rodadas (conforme dados já apresentados), o que garante a elas aumento de lucratividade para novas atividades de $\mathrm{P} \& \mathrm{D}$ e manutenção de posicionamento. Pode-se constatar ainda pela análise da tabela:

1) Melhoria nos resultados financeiros das empresas imitadoras, principalmente no estágio de maturidade da indústria. Essas conseguiram alcançar maiores participações de mercado (+21\%) e melhores indicadores financeiros em detrimento, principalmente, da redução de relevância das empresas inovadoras;

2) Esse melhor resultado das firmas imitadoras contribuiu para o incremento na quantidade média de patentes depositadas em relação à Parametrização Inicial, da ordem de $13 \%$ e $25 \%$ nos estágios inicial e maturidade, respectivamente;

3) Os preços também apresentam viés de alta em relação à Parametrização Inicial. Tal resultado deve ser entendido como uma inflação de demanda pelos produtos das empresas imitadoras, que diminuiu a concorrência via preços do mercado;

4) Além do resultado favorável às empresas imitadoras, o novo tipo de comportamento do consumidor Grupo 3 estabelece melhores resultados também para as empresas competitivas, especializadas em medicamentos genéricos, pelo menos no que tange à sua lucratividade $(+710 \%$ e $+478 \%$ nos estágios inicial e maturidade, respectivamente). Esse resultado é ainda melhor que o resultado 
alcançado na mudança de parametrização do Governo, basicamente pelos dois efeitos que a nova parametrização impôs: primeiro, pela preferência via preço, e depois pelo efeito indireto do aumento de inovações.

O cenário apresentado na simulação acima expõe uma relevância considerável para empresas que procuram inserir inovações incrementais no mercado, e essa constatação é conexa à relevância da estratégia de introdução desse tipo de produto observada empiricamente na indústria farmacêutica (Gilbert, Henske; Ashish, 2003; Love, 2003; Ganuza et al., 2009). O sucesso de políticas de acesso da população a produtos inovadores via barateamento de preços - justamente a política dos medicamentos genéricos - parece ter obtido sucesso até nas populações com renda superior, com uma modificação de sua elasticidade-preço da demanda (tornando a demanda mais elástica a preços), mas com relevância na comparação da qualidade.

Nesse cenário, a melhor estratégia a ser perseguida por uma empresa que busca inovações tem se firmado como a estratégia incremental, inserindo novos produtos que, apesar de serem apenas marginalmente melhorados, possuem uma relação risco-retorno mais compatível com a realidade industrial.

\subsubsection{Estratégia de Marketing: mudança das características de escolha do demandante Grupo 2}

Nesse novo exercício, a ideia é verificar como as estratégias das firmas inovadoras no que tange ao marketing de seus produtos poderão prover mudanças nos resultados de mercado. Imagine agora que, diferente do exercício realizado no tópico anterior, seja procurada pelas empresas inovadoras a diferenciação - mesmo que algumas vezes espúria - de seus produtos, buscando inserir na ordenação de preferência dos consumidores do Grupo 2 um padrão de escolha pautado primeiramente na análise das características tecnológicas. A nova ordenação de preferências e parâmetros dos consumidores do Grupo 2 segue no Quadro 7.

\section{Quadro 7}

Ordem de preferência e parâmetros $\boldsymbol{\tau}$ e $\Delta$ para o consumidor Grupo 2 -

Parametrização inicial e parametrização Grupo 2

\begin{tabular}{|c|c|c|c|c|c|}
\hline \multirow{2}{*}{ Grupo } & & $v_{1}^{i}$ & $v_{2}^{i}$ & $v_{3}^{i}$ & $v_{4}^{i}$ \\
\cline { 2 - 6 } & $\mathrm{N}$ & Preço & $\begin{array}{c}\text { Tempo de } \\
\text { Eficácia }\end{array}$ & $\begin{array}{c}\text { Reação } \\
\text { Adversa }\end{array}$ & $\begin{array}{c}\text { Efeito } \\
\text { Colateral }\end{array}$ \\
\hline Parametrização Inicial & 375 & 1 & 2 & 3 & 4 \\
\hline \multirow{2}{*}{ G2 - Famílias decis 1 a 3 } & $\tau$ & 0,05 & 0,95 & 0,95 & 0,95 \\
\cline { 2 - 6 } & $\Delta$ & 0,05 & 0,05 & 0,05 & 0,05 \\
\hline Parametrização Grupo 2 & 375 & 4 & 3 & 2 & 1 \\
\hline \multirow{2}{*}{ G2 - Famílias decis 1 a 3 } & $\tau$ & 0,10 & 0,10 & 0,10 & 0,10 \\
\cline { 2 - 6 } & $\Delta$ & 0,05 & 0,05 & 0,05 & 0,05 \\
\hline
\end{tabular}

Fonte: Elaboração própria. 
Agora os consumidores do Grupo 2 são menos tolerantes a preços maiores como antes, mas mostram menos tolerância também em aceitar produtos com características inferiores. Os erros de percepção continuarão a ser supostos $\Delta=0,05$, indicando ainda o menor grau de informação dos demandantes (comparando com os demandantes do Grupo 3).

Essa nova conformação da demanda expressa um forte viés concentrador em prol das empresas inovadoras, com um aumento de participação de mercado de $36 \%$ na média das classes terapêuticas, a se comparar com a Parametrização Inicial. Claramente, com a estratégia de marketing que modificou os padrões de decisão da demanda do Grupo 2, essas empresas puderam estabelecer um alto grau de oligopólio com aumento de participação de empresas imitadoras e inovadoras, que só diminui quando os genéricos são ofertados.

A Tabela 4 apresenta a comparação para a média de toda a indústria.

Tabela 4

Indicadores econômicos, financeiros e de tecnologia da indústria farmacêutica - parametrização Grupo 2 (média das classes terapêuticas)

\begin{tabular}{|c|c|c|c|c|c|c|}
\hline \multirow{2}{*}{ Firmas } & \multicolumn{3}{|c|}{ Estágio Inicial (0-200) } & \multicolumn{3}{|c|}{ Estágio Maturidade (201-400) } \\
\hline & Inovadoras & Imitadoras & Competitivas & Inovadoras & Imitadoras & Competitivas \\
\hline Receita vendas média & $+17 \%$ & $-32 \%$ & $-21 \%$ & $+28 \%$ & $+1234 \%$ & $+5 \%$ \\
\hline Lucro médio & $+11 \%$ & $+250 \%$ & $-60 \%$ & $+95 \%$ & $+2317 \%$ & $+35 \%$ \\
\hline Preço médio & $+14 \%$ & $+9 \%$ & $+20 \%$ & $+23 \%$ & $+12 \%$ & $+57 \%$ \\
\hline $\begin{array}{l}\text { Número de produtos } \\
\text { médio }\end{array}$ & $-17 \%$ & $0 \%$ & $-22 \%$ & $-23 \%$ & $0 \%$ & $-28 \%$ \\
\hline $\begin{array}{l}\text { Receita vendas média } \\
\text { / produto }\end{array}$ & $+42 \%$ & $-32 \%$ & $+1 \%$ & $+67 \%$ & $+1234 \%$ & $+44 \%$ \\
\hline $\begin{array}{l}\text { Lucro médio / } \\
\text { produto }\end{array}$ & $+35 \%$ & $+250 \%$ & $-49 \%$ & $+110 \%$ & $+2317 \%$ & $+86 \%$ \\
\hline $\begin{array}{l}\text { Número médio de } \\
\text { Patentes }\end{array}$ & \multicolumn{3}{|c|}{$-13 \%$} & \multicolumn{3}{|c|}{$+25 \%$} \\
\hline
\end{tabular}

Nota: O número médio de patentes é estabelecido para todo o mercado, não sendo diferenciado por tipo de empresa.

Fonte: Elaboração própria. 
Pode-se constatar:

A estratégia de diferenciação via marketing aumenta a lucratividade para todos os tipos de empresa, basicamente porque eleva o preço médio da indústria;

Para o mercado, porém, é uma estratégia que diminui o número de produtos inovadores e, consequentemente, o número de produtos ofertados por todas as empresas;

Caso as empresas inovadoras consigam estabelecer uma estratégia de diferenciação, na qual os consumidores do Grupo 2 agora sejam levados a observar inicialmente as características tecnológicas dos produtos, os resultados de mercado apresentam melhoria para as empresas, mas a expensas de menor escopo de produtos no mercado e preços mais elevados, em clara constatação de diminuição do bem estar dos consumidores.

\section{Considerações Finais}

Neste trabalho foi estabelecido um modelo evolucionário History-friendly para a indústria farmacêutica, com replicações de características específicas ao mercado brasileiro. O ponto de enfoque dessa estratégia de análise foi demonstrar a relevância que diferentes especificações da demanda têm sobre os resultados econômicos e tecnológicos em indústrias com elevado grau de desenvolvimento tecnológico, nos moldes das questões levantadas por Nelson (2013).

Nos últimos anos, nota-se um movimento setorial onde firmas inovadoras têm procurado estabelecer capacidade produtiva na fabricação de genéricos, como forma de diminuir a queda de lucratividade após a expiração de patentes. Ainda, mostrou-se necessário estabelecer novas formas de realização de $\mathrm{P} \& \mathrm{D}$, com partilhas de risco, estabelecimento de joint-venture, entre outros. Empresas fabricantes de genéricos, com o aumento da lucratividade de seus negócios, têm vislumbrado novas estratégias para desenvolvimento de novos produtos, galgando assim novas capacitações que não seriam possíveis caso não existisse a cópia dos produtos e a aceitação da demanda na intercambialidade desses com os medicamentos de referência.

Nesse contexto, procurou-se aqui apresentar como modificações nos parâmetros da demanda ajudam a explicar a conformação estrutural e também a necessidade - ou possibilidade - de atualização das estratégias competitivas empresariais. O modelo, baseado no estudo de caso da indústria farmacêutica com fortes especificações do contexto brasileiro, teve o objetivo de demonstrar a relevância que diferentes especificações da demanda têm sobre os resultados econômicos e tecnológicos em indústrias com elevado grau de desenvolvimento tecnológico. Segundo os resultados do modelo, os atributos de escolha dos consumidores - e as mudanças destes - ajudam a explicar os resultados sobre o 
desempenho das empresas e bem-estar dos demandantes sob diferentes estratégias competitivas, políticas industriais e/ou mudanças na legislação vigente.

A Parametrização Inicial sugerida no modelo corresponde a uma aproximação da verificação empírica da indústria farmacêutica no que tange às especificações de preferência, tolerância e reconhecimento das características dos demandantes. Os resultados demonstram como essa parametrização impacta e define os resultados favoráveis às empresas competitivas, produtoras de medicamentos genéricos, e como o lucro das empresas inovadoras é erodido nessa situação, resultado esse que está em profunda consonância com as movimentações realizadas pelas empresas no cenário nacional.

Firmas inovadoras procuram estabelecer capacidade produtiva na fabricação de genéricos, como forma de diminuir a queda de lucratividade após a expiração de patentes. Ainda, tais firmas têm estabelecido novas formas de realização de P\&D, com partilhas de risco, estabelecimento de joint-venture, entre outros. Empresas fabricantes de genéricos, com o aumento da lucratividade, têm vislumbrado novas estratégias para desenvolvimento de novos produtos, galgando assim novas capacitações que não seriam possíveis caso não existisse a cópia dos produtos e a aceitação da demanda na intercambialidade desses com os medicamentos de referência.

As modificações nos parâmetros da demanda também foram capazes de explicar a necessidade de utilização de novas estratégias competitivas. Uma nova parametrização com importância maior para a variável preço indicou, além da maior participação de mercado da linha de medicamentos genéricos, a necessidade do estabelecimento de uma estratégia de inovação pautada em inovações incrementais, que permitam menores custos de desenvolvimento e P\&D e uma relação riscoretorno mais aceitável. As empresas da indústria farmacêutica têm utilizado esse expediente frequentemente.

Ainda, conforme verificado na modificação do padrão de compra do Governo, uma estratégia de política industrial que busque favorecer as empresas inovadoras - com o estabelecimento de padrões que analisam as características tecnológicas no processo de licitação - pode ser interessante para seu objetivo: resultados do modelo mostram que essa especificação também permite uma lucratividade maior para empresas imitadoras, um aumento do número de produtos disponibilizados no mercado e, ainda, resultados melhores para empresas de genéricos, principalmente em prazos mais longos de tempo, pelo aumento das inovações geradas. A se considerar o tipo de inovação realizado pelas empresas nacionais vis a vis empresas multinacionais - e os valores despendidos como parcela da receita de vendas - pode-se concluir pela viabilidade dessa política industrial. 
Nesse cenário, às empresas inovadoras cabe a estratégia de modificação das preferências dos consumidores de renda inferior através de marketing. Nesse caso, contudo, há efeito danoso para o bem estar da economia: aumento de preço médio de produtos e diminuição de número de produtos genéricos.

Em suma, os resultados destacam a importância da consideração da demanda nos modelos evolucionários e são conclusivos nesse objetivo. Mudanças consideráveis nos resultados de mercado, financeiros e tecnológicos de firmas industriais foram alcançadas com modificações na parametrização dos consumidores, exatamente o modo como estes balizam suas escolhas. Para esse fim, porém, foram utilizadas algumas limitações modelísticas que devem ser superadas e suprimidas em novos estudos. De qualquer forma, considerações preliminares para trabalhos desse tipo estão lançadas, na espera que rendam frutos no desenvolvimento de novos modelos evolucionários.

\section{Referências bibliográficas}

ABERNATHY, W. J.; UTTERBACK, J. M. Patterns of industrial innovation. Technological Review, v. 80, n. 7, p. 40-47, 1978.

ACS, Z. J.; AUDRETCH, D. B. Innovation, market structure and firm size. Review Economical and Statistical, v. 69, n. 4, p. 567-574, 1987.

ANDERSEN, E. S. Schumpeter's core works revisited: resolved problems and remaining challenges. Journal of Evolutionary Economics, v. 22, n. 4, p. 621-625, Springer 2012.

ANGELL, M. Excess in the pharmaceutical industry. Canadian Medical Association, CMAJ, v. 171, n. 12, Dec. 7, 2004.

AUDRETCH, D. B. Innovation and industry evolution. Cambridge, MA: MIT Press, 1995.

AVERSI, R.; DOSI, G.; FAGIOLO, G.; MEACCI, M.; OLIVETTI, C. Demand dynamics with socially evolving preferences. Industrial and Corporate Change, v. 8, n. 2, p. 353-408, 1999.

BRASIL. DECRETO N. 7.713, DE 03 DE ABRIL DE 2012. Estabelece a aplicação de margem de preferência nas licitações realizadas no âmbito da Administração Pública Federal para aquisição de fármacos e medicamentos descritos no Anexo I, para fins do disposto no art. $3^{\circ}$ da Lei no 8.666, de 21 de junho de 1993. 2012.

CADE. Ato de concentração Sanofi-Aventis e Medley (AC n. 08012.003189/200910). Voto e Relatório sobre Aquisição. Brasília: Conselho Administrativo de Defesa Econômica (CADE), 2009. 
CADE. Ato de Concentração Pfizer e Teuto (AC n. 08012.011801/2010-53). Voto e Relatório sobre Aquisição. Brasília, Conselho Administrativo de Defesa Econômica (CADE), 2010.

CALIARI, T.; RUIZ, R. M. Brazilian pharmaceutical industry and generic drugs policy: impacts on structure and innovation and recent developments. Science \& Public Policy (Print), v. 1, p. 1-12, 2013.

CALIARI, T.; RUIZ, R. M.; VALENTE, M. Heterogeneity of demand and product innovation. Estudos Econômicos, São Paulo, v. 47, n. 1, p. 5-37, 2017.

CHANDLER, A. D. Scale and scope: the dynamics of industrial capitalism. Cambridge, Mass.: The Belknap Press of Harvard University Press, 1999.

DINIZ, B. P. C.; SERVO, L. M.; PIOLA, S. F.; EIRADO, M. Gastos das famílias com saúde no Brasil: evolução e debate sobre gasto catastrófico. In: SILVEIRA, F. G.; SERVO, L. M.; MENEZES, T.; PIOLA, S. F. Gasto e consumo das famílias brasileiras contemporâneas. Brasília: Ipea, 2007. v. 2, 552 p.

DOSI, G. Sources, procedures, and microeconomic effects of innovation. Journal of Economic Literature, v. 26, n. 3, p. 1120-1171, Sept., 1988.

GAGNON, M.A.; LEXCHIN, J. The cost of pushing pills: a new estimate of pharmaceutical promotion expenditures in the United States. PLoS Med, v. 5, n. 1, 2008.

GANUZA, J. J.; LLOBET, G.; DOMÍNGUEZ, B. R\&D in the pharmaceutical industry: a world of small innovations. Management Science, v. 55, n. 4, p. 539-551, Apr. 2009.

GARAVAGLIA, C.; MALERBA, F.; ORSENIGO, L.; PEZZONI, M. Technological regimes and demand structure in the evolution of the pharmaceutical industry. Journal of Evolutionary Economics, v. 22, p. 677-709, 2012.

GARCIA, L. P.; MAGALHÃES, L. C. G.; SANT'ANNA, A. C.; FREITAS, L. R. S.; AUREA, A. P. Dimensões do acesso a medicamentos no Brasil: perfil e desigualdades dos gastos das famílias, segundo as pesquisas de orçamentos familiares 2002-2003 e 2008-2009. Rio de Janeiro: Ipea, jun. 2013. 53p. (Texto para Discussão, n. 1839).

GILBERT, J.; HENSKE, P.; ASHISH. Rebuilding big pharma's business model. VIVO - The Business \& Medicine Report, v. 21, n. 10, Nov. 2003.

KLEPPER, S. Exit, entry, growth and innovation over the product life-cycle. American Economic Review, v. 86, n. 3, p. 562-583, 1996. 
KLEPPER, S.; SIMONS, K. L. Technological extinctions of industrial firms: an enquiry into their nature and causes. Industrial and Corporate Change, v. 6, n. 2, p. 379-460, 1997.

LEVIN, R. C.; COHEN, W. M.; MOWERY, D. C. R\&D appropriability, opportunity, and market structure: new evidence on some Schumpeterian hypotheses. The American Economic Review, v. 75, n. 2, Papers and Proceedings of the Ninety Seventh Annual Meeting of the American Economic Association p. 2024, May, 1985.

LEVIN, R.; COHEN, W. M.; MOWERY, D. C. Survey research on R\&D appropriability and technological opportunity. Part 1: appropriability. New Haven, CT: Yale University Press, 1984.

LOVE, J. Evidence regarding research and development investment in innovative and non-innovative medicines. 2003. Disponível em: http://www.cptech.org/ip/health/rnd/evidenceregardingrnd.pdf. Acesso em: 20 jul. 2013.

MALERBA, F.; NELSON, R.; ORSENIGO, L.; WINTER, S. Demand, innovation, and the dynamics of market structure: the role of experimental users and diverse preferences. Journal of Evolutionary Economics, v. 17, p. 371-399, 2007.

MALERBA, F.; ORSENIGO, L. Innovation and market structure in the dynamics of the pharmaceutical industry and biotechnology: toward a history-friendly model. Industrial and Corporate Change, v. 12, n. 4, p. 667-703, 2002.

MALERBA, F.; NELSON, R.; ORSENIGO, L.; WINTER, S. Innovation and the evolution of industries: history-friendly models. Cambridge University Press, 2016. 292 p.

MAZZUCATO, M. A computational model of economies of scale and market share instability. Structural Change and Economic Dynamics, v. 9, p. 55-83, 1998.

NELSON, R. Demand, supply, and their interaction on markets, as seen from the perspective of evolutionary economic theory. Journal of Evolutionary Economics, v. 23, p. 17-38, 2013.

NELSON, R. R., WINTER, S. G. Uma teoria evolucionária da mudança econômica. Campinas: Editora Unicamp, 1982. 631p.

NELSON, R., CONSOLI, D. An evolutionary theory of household consumption behavior. Journal of Evolutionary Economics, v. 20, n. 5, p. 665-87, 2010.

OLSHAVSKY, R. W., GRANBOIS, D. H. Consumer decision making - Fact or fiction? Journal of Consumer Research, v. 6, p. 93-100, 1979. 
PAVITT, K. Sectoral patterns of technical change: towards a taxonomy and a theory. Research Policy, v. 13, p. 343-373, 1984.

RUIZ, R. M.; CALIARI, T; AMARAL, P. V.; DOMINGUES, E. P.; ARAÚJO, R. O complexo industrial da saúde. In: De NEGRI, J.A.; LEMOS, M. B. (Org.). $O$ núcleo tecnológico da indústria brasileira. Brasília: Ipea, 2011. v. 2.

SCHERER, F. M. Pricing, profits, and technological progress in the pharmaceutical industry. Journal of Economic Perspectives, v. 7, n. 3, p. 97-115, 1993.

SCHMOOKLER, J. Invention and economic growth. Cambridge: Harvard University Press, 1966.

SILVERBERG, G.; DOSI, G.; ORSENINGO, L., Innovation, diversity and diffusion: a self organization model. Economic Journal, v. 98, n. 393, p. 1032-1054, 1988.

SIMON, H. A. A behavioral model of rational choice. The Quarterly Journal of Economics, v. 69, n. 1, p. 99-118, Feb. 1955.

SIMON, H. A. From substantive to procedural rationality. In: LATSIS, S. J. (Ed.). Method and appraisal in economics. Cambridge: Cambridge University Press, 1976. p. 129-148.

SIMON, H. A. Rationality as process and as product of thought. American Economic Review, v. 68, n. 2, p. 1-16, 1978.

SIMON, H. A. Rational decision making in business organizations. [Nobel Memorial Lecture]. American Economic Review, v. 69, n. 4, p. 493-513, Sept. 1979.

SLOVIC, P. Choice. In: OSHERSON, D. N.; SMITH, E. E. (Ed.). An invitation to cognitive science. Cambridge, MA: MIT Press, 1990.

STIGLER, G. The economics of information. The Journal of Political Economy, v. 69, n. 3, p. 213-225, Jun. 1961.

SUTTON, J. Technology and market structure: theory and history. Cambridge, MA: MIT Press, 1998. 676p.

THALER, R. H. The winner's curse: paradoxes and anomalies of economics life. New York: Free Press, 1992.

TVERSKY, A.; KAHNEMAN, D. Rational choice and the framing of decisions. Journal of Business, v. 59, p. 251-278, 1986.

VALENTE, M. Pseudo-NK: an enhanced model of complexity. Nov, 2008. (LEM Working Paper Series, 2008/26). Disponível em: https://www.econstor.eu/handle/10419/89504. 
VALENTE, M. Evolutionary demand: a model for boundedly rational consumers. Journal of Evolutionary Economics, v. 22, p. 1029-1080, 2012.

VALOR ECONOMICO. Concorrência de genéricos pressiona resultado da Sanofi Aventis. 2013. Disponível em: http://www.valor.com.br/empresas/3219290/concorrencia-de-genericos-pressionaresultado-da-sanofi-aventis. Acesso em: 2 ago. 2013.

WINDRUM, P.; BIRCHENHALL, C. Is product life cycle theory a special case? Dominant designs and the emergence of market niches through coevolutionarylearning. Structural Change and Economic Dynamics, v. 9, p. 109-134, 1998.

WINDRUM, P.; CIARLI, T.; BIRCHENHALL, C. Consumer heterogeneity and the development of environmentally friendly technologies, Technological Forecasting and Social Change, v. 76, n. 4, p. 533-551, 2009.

WILLIAMSON, O. E. The theory of the firm as governance structure: from choice to contract. Berkeley: University of California, Jan. 2002.

WINTER, S. Schumpeterian competition in alternative technological regimes. Journal of Economic Behavior and Organization, v. 5, n. 3-4, p. 287-320, 1984. 